\title{
Techniques for postmortem tenderisation in meat processing: effectiveness, application and possible mechanisms
}

\author{
Haibo Shi ${ }^{1}$, Fereidoon Shahidi ${ }^{2}$, Jiankang Wang ${ }^{3}$, Yan Huang ${ }^{1}$, Ye Zou ${ }^{1 *}$, Weimin $\mathrm{Xu}^{1}$ and Daoying Wang ${ }^{1^{*}}$ (D)
}

\begin{abstract}
Developing efficient and promising tenderising techniques for postmortem meat is a heavily researched topic among meat scientists as consumers are willing to pay more for guaranteed tender meat. However, emerging tenderising techniques are not broadly used in the meat industry and, to some degree, are controversial due to lack of theoretical support. Thus, understanding the mechanisms involved in postmortem tenderisation is essential. This article first provides an overview of the relationship of ageing tenderisation and calpain system, as well as proteomics applied to identify protein biomarkers characterizing tenderness. In general, the ageing tenderisation is mediated by multiple biochemical activities, and it can exhibit better palatability and commercial benefit by combining other interventions. The calpain system plays a key role in ageing tenderisation functions by rupturing myofibrils and regulating proteolysis, glycolysis, apoptosis and metabolic modification. Additionally, tenderising techniques from different aspects including exogenous enzymes, chemistry, physics and the combined methods are discussed in depth. Particularly, innovation of home cooking could be recommended to prepare relatively tender meat due to its convenience and ease of operation by consumers. Furthermore, the combined interventions provide better performance in controlled tenderness. Finally, future trends in developing new tenderising techniques, and applied consideration in the meat processing industry are proposed in order to improve meat quality with higher economical value.
\end{abstract}

Keywords: Postmortem tenderisation, Ageing, Emerging technique, Combination intervention, Functionary mechanism

\section{Introduction}

Tenderness is a crucial palatable quality affecting consumers' preference to meat products (Miller et al. 2001), and the upgrading of low-value meat with guaranteed tenderness will favor products with higher price (Zhu et al. 2019). Particularly, from the perspective of dietary evaluation, products displaying harder chewiness deter the elderly from consuming. Thus, meat scientists have been committed to improving meat tenderness in order to increase the repeat purchase desire of consumers and

\footnotetext{
* Correspondence: zouye@jaas.ac.cn; daoyingwang@yahoo.com ${ }^{1}$ Institute of Agricultural Products Processing, Jiangsu Academy of Agricultural Sciences, Nanjing 210014, People's Republic of China Full list of author information is available at the end of the article
}

to produce better sensorially acceptable meat products (Li et al. 2012).

The up-regulation of pre-slaughter tenderness is affected by rearing practices (breed, sex, genotype, nutrition and age), and also by muscle structure and composition (Devlin et al. 2017). This review mainly focuses on the postmortem tenderisation based on the perspective of meat processing. Typically, the fragmentation of muscle structural and associated proteins (e.g., myosin, actin, collagen and elastin) mediated by endogenous protease (e.g., calpain), as well as the continuous degradation of cytoskeleton proteins and the energy metabolism can increase postmortem tenderness (Koohmaraie \& Geesink 2006; Purslow 1994; Taylor, Geesink, et al. 1995; Thompson et al. 2006; Wheeler \& Koohmaraie 1994). Moreover,

(c) The Author(s). 2021 Open Access This article is licensed under a Creative Commons Attribution 4.0 International License, which permits use, sharing, adaptation, distribution and reproduction in any medium or format, as long as you give appropriate credit to the original author(s) and the source, provide a link to the Creative Commons licence, and indicate if changes were made. The images or other third party material in this article are included in the article's Creative Commons licence, unless indicated otherwise in a credit line to the material. If material is not included in the article's Creative Commons licence and your intended use is not permitted by statutory regulation or exceeds the permitted use, you will need to obtain permission directly from the copyright holder. To view a copy of this licence, visit http://creativecommons.org/licenses/by/4.0/. 
ageing tenderisation is widely used in meat industries, and postmortem ageing is a value-added process of obtaining better tenderness and flavor (Wang et al. 2013). Comprehensive understanding of the relationship between endogenous proteases and postmortem ageing will render people to design targeted interventions for better tenderness. It has to be mentioned that applying proteomics to identify protein biomarkers characterizing tenderness is conductive to deeply understanding the complex biological pathways and non-destructively predicting the tenderness development (Lametsch \& Bendixen 2001; Montowska \& Pospiech 2013; Picard et al. 2014). Nevertheless, high-quality meat tenderness based on ageing tenderisation is often at the expense of sufficient time, larger storage space and higher energy consumption. The drawbacks of ageing tenderisation require the use of other tenderising techniques to meet the demand.

Different feeding diets and farming management interventions of animals are commonly used to modify preslaughter muscle tenderness, which are a systematic and time-consuming process (Cao et al. 2014). By contrast, different types of tenderising techniques are developed for postmortem meat that are short-term and effectively produce high-quality commercial products. Current techniques for postmortem tenderisation can be classified into enzymatic, chemical, physical and combined categories (Al-Hilphy et al. 2020; Bekhit et al. 2014; Dominguez-Hernandez et al. 2018; Ray et al. 2016; Taylor \& Hopkins 2011). Of them, some techniques cannot achieve the similar tenderising trend, which may be ascribed to the difference of materials (e.g., feeding conditions and slaughtered status) and equipment performance (Arroyo, Lascorz, et al. 2015; Christensen et al. 2013; Faridnia et al. 2014; Giménez et al. 2015; Saleem \& Ahmad, 2016; Zou et al. 2018). Moreover, the implementation of these interventions in meat industry is limited by the willingness of operators, technological aspects or input costs, and actual benefits (Bhat et al. 2018; Warner et al. 2017). Hence, understanding how each technology induces the improved tenderness of postmortem meat will favor the scientists and manufacturers to produce more guaranteed tender meat. However, few available literatures have systematically evaluated the postmortem tenderising techniques based on multidimensional analyses (e.g., graphical representation, functionary mechanism, existing shortcomings and upgraded strategies).

In this article, a brief review on the relationship between ageing tenderisation and the calpain system, as well as protein biomarkers that characterize postmortem tenderness, are also discussed. Subsequently, postmortem tenderisation solutions from the four common (enzymatic, chemical, physical and combined) categories with principles and existing problems are discussed in detail, in order to provide effective guidance for production. Finally, suggestions are made concerning the future trends in the development of new tenderising strategies (e.g., efficiency-integrated equipment, non-destructive evaluation models or database, adjustion to the targeted market, and more accessible and easier operating technologies for consumers), as well as posing and responding to their applied considerations in the meat processing industry.

\section{Ageing tenderisation, calpain system and protein biomarkers}

For connective tissues (especially the intramuscular connective tissue, IMCT), it has been broadly accepted that their amount and solubility in muscle are responsible for meat tenderness (Christensen et al. 2013). However, the contribution of connective tissue to tenderness depends mainly on the development of heat-stable cross-links and the total collagen content that are predominantly established before slaughter (Harper 1999; Warner et al. 2010). During postmortem ageing, proteoglycans of IMCT linking collagen fibrils and stabilizing the IMCT are degraded, resulting in weaker linkage between collagen fibrils and better texture (Nishimura et al. 1996). Therefore, although the contribution of IMCT to meat texture is certainly important, it has been thought to be rather immutable compared to myofibrils during postmortem ageing (Nishimura 2015), which is outside the scope of the present review.

Sarcomere length of postmortem muscle is also correlated with meat tenderness, and moderate post-slaughter temperature passing into rigor mortis will produce the smallest contraction of sarcomere for increased tenderness (Ertbjerg \& Puolanne 2017; Smulders et al. 1990). A minimum shortening (10\%) can be observed at 14 to $19{ }^{\circ} \mathrm{C}$ and $\mathrm{Ca}^{2+}$ release from the tubes of sarcoplasmic reticulum (SR) into sarcoplasm will be stimulated as the temperature falls from 15 to $0{ }^{\circ} \mathrm{C}$ (cold shortening) (Locker \& Hagyard 1963). The mechanism of cold shortening is associated with diminished functioning at low temperatures of the $\mathrm{Ca}^{2+}$ pumps in SR. SR accompanies with mitochondria to maintain the free $\mathrm{Ca}^{2+}$ concentration at a low level, which is mediated by hydrolysis of ATP (Ertbjerg \& Puolann 2017). Thus the impaired $\mathrm{Ca}^{2+}$-accumulating ability of these two organelles will decrease the level of ATP concentration, inducing the formation of actomyosin complex to prevent sliding of actin and myosin filaments. As a result, the changes in extensibility and formation of cross-links (myosin S-1 filament and actin) are accompanied by muscle shortening, causing longer distances between longitudinal filaments and lower electrostatic repulsion. However, the water accessible surface areas of S-1 and S-2 units in myosin filament constitute higher proportion of actomyosin, 
and they do not change much with sarcomere length and not combine with actin (Puolanne \& Halonen 2010). Thus, their role in water retention should be considered. Meanwhile, the muscle types (larger or little carcass, red or white meat) must be taken into account when analyzing the effects of temperature on sarcomere length due to their difference in thermal conductivity coefficient (Jacob \& Hopkins 2014). Ageing tenderisation has been studied for a long time, and many theories have emerged, such as those of calpain, calcium tension, calcium ion, and cathepsin. Among these theories, the relationship between muscle ageing and the calpain system has received much attention and gradually considered as the mainstream concept.

\section{Ageing tenderisation}

The physiological and biochemical effects on postmortem muscle (such as rigor and ageing) could influence meat tenderness and water-holding capacity (WHC). Studies have provided convincing evidence that the developed tenderness during ageing is due to postmortem proteolysis of key structural proteins (e.g., desmin, titin, and troponin-T) and structural changes of sarcomeres (Taylor, Geesink, et al. 1995; Wheeler \& Koohmaraie 1994). However, to obtain value-added meat products, postmortem muscle undergoing the ageing process is essential and will effectively undergo tenderisation by activating endogenous proteolytic enzymes.

Postmortem ageing can influence meat tenderness, flavor and WHC. The proposed mechanisms for muscle ageing are shown in Fig. 1 in which (1) calpain system plays a leading role in the process of muscle ageing or tenderisation (discussed in section of calpain system and tenderising mechanism), and $\mathrm{Ca}^{2+}$ plays an indirect role by activating calpain (Stamler et al. 2001); (2) considering that apoptosis, rather than rigor mortis, is the initial phase in the conversion of muscle to meat, cellular changes associated with apoptosis are believed to be intrinsically linked to tenderness. Apoptotic enzymes participate in the early stages of muscle ageing, displaying the degradation of titin and nebulin, as well as regulation of the $\mathrm{Ca}^{2+}$-activated enzyme system (Huang et al. 2011; Huang et al. 2017; Kemp \& Parr 2012; Wang et al. 2018). Apoptotic enzymes, such as caspase-3, can be activated by denitrification to induce apoptosis for myofibril fragmentation (Wu et al. 2015). Moreover, caspase-3 has direct proteolytic activity against calpastatin (Mandic et al. 2002; Pörn-Ares et al. 1998); (3) calpain is a cysteine protease, and the cysteine residue in its active site can be modified by protein S-nitrosylation, consequently affecting its autolysis and proteolytic activity (Hou et al., 2020; Li, Liu, et al. 2014). Upon protein S-nitrosylation, the release speed of $\mathrm{Ca}^{2+}$ is also influenced by modifying

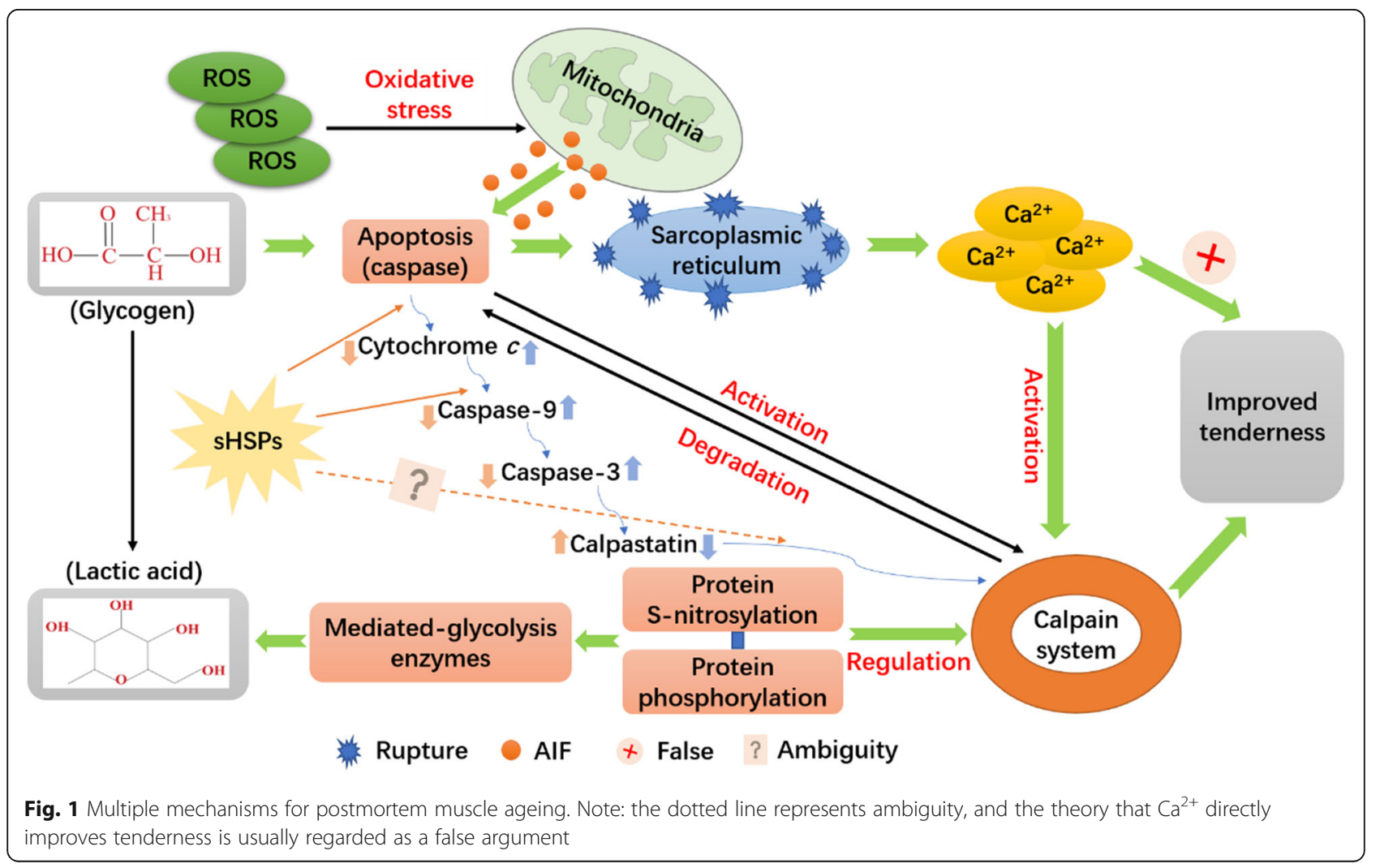


the corresponding release channels, which may lead to muscle contraction and different moisture distribution in myofibrils (Wang et al. 2010). Additionally, the activity of enzymes (e.g., phosphofructokinase) involved in postmortem glycolysis can be inhibited by S-nitrosylation, thus affecting the decline rate of $\mathrm{pH}$, ultimate $\mathrm{pH}$, and the quality of aged meat (Liu et al. 2016); and (4) as outlined in the section of calpain system and tenderising mechanism, the modification of protein phosphorylation exerts an important role in the postmortem ageing.

With the emergence of new studies, the mechanisms involved in muscle ageing related to tenderness are being further clarified. It has recently been reported that calpain, rather than other proteases, participates in regulating myowater properties in the early stages of postmortem ageing (before $4 \mathrm{~d}$ ), and calpain degrades desmin and integrin, where the latter interestingly restrains the formation of drip channels for water retention to improve tenderness (Qian et al. 2020). Postmortem ageing is an oxidative stress process that generates reactive oxygen species (ROS), which can induce apoptosis (Zhang et al. 2018). Several studies have confirmed that some of the released apoptotic proteins from mitochondrial pathways (classical apoptotic pathway) participate in regulating apoptosis (Desagher \& Martinou 2000). Among these proteins, cytochrome $c$ (Cytc) is widely studied, and few reports have focused on apoptosis-inducing factor (AIF) (Wang et al. 2018; Zhang et al. 2017). Chen et al. (2020) reported that ROS-induced oxidative stress accompanied by decreased $\mathrm{pH}$ and ATP consumption contributes to the released-AIF level by enhancing mitochondrial membrane permeability, further improving muscle tenderness. Comprehensive understanding of ROS-induced oxidative stress enhances the development of innovative tenderising interventions by altering the internal oxidation environment of postmortem muscle.

Moreover, small heat shock proteins (sHSPs) are chaperone proteins produced by organism, which play a protective role in anti-apoptotic activity (Ba et al. 2015). sHSPs have been found to be involved in the delay of the ageing tenderising process (i.e., contributing to meat toughness) by inhibiting the onset of apoptosis via possible interactions with multiple apoptotic cascades (e.g., binding directly to Cytc and caspase-3) (Cramer et al. 2018). However, its variable expressions in muscles with different ultimate $\mathrm{pH}(\mathrm{pHu})$ need further studies (Lomiwes et al. 2014a). sHSPs increasingly associate with myofibrils as the $\mathrm{pH}$ declines from physiological levels (Fig. 2a). When the

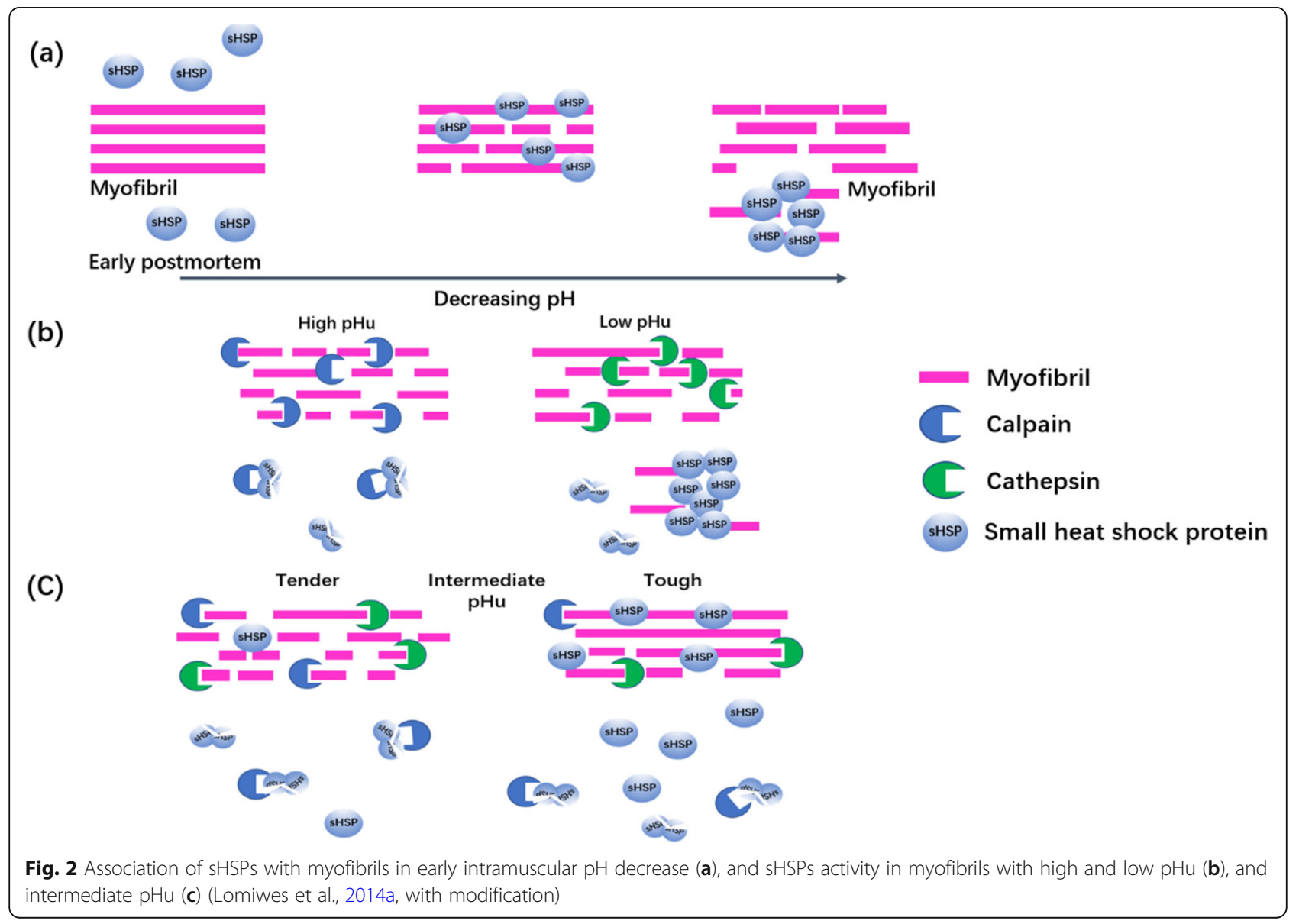


decreasing muscle $\mathrm{pH}$ exceeds the isoelectric points of sHSPs, they will aggregate and precipitate into sarcoplasm. sHSPs do not associate with myofibrils in high $\mathrm{pHu}$ meat but act as an alternative substrate to $\mu$-calpain, which possesses high activity. In low pHu meat, sHSPs come to aggregate accompanied by the low $\mu$-calpain and high cathepsin activities, contributing to meat tenderisation (Fig. 2b). Furthermore, sHSPs can protect the structural integrity of muscle by binding to myofibrils and stabilizing unfolded proteins. Kim et al. (2008) reported that although $\mu$-calpain and cathepsin activity is least optimal in intermediate $\mathrm{pHu}$ meat, there exists still sufficient proteolytic activity to degrade myofibrillar protein (MP) for acceptable tenderness (Fig. 2c). However, high levels of sHSPs inducing tough meat may also occur in intermediate $\mathrm{pHu}$ meat by further inhibiting the $\mu$-calpain proteolytic ability, acting as an alternative substrate to prevent extensive degradation of myofibrils. Additionally, the muscle-specific proteolysis in sHSPs changes with the unique metabolic features of each muscle type (Ma \& Kim 2020).

Ageing tenderisation is widely used in the meat processing industry, and strategies (e.g., dry ageing in a bag and wet ageing) based on the temperature-ageing time are well developed for controlled tenderness (Hwang et al. 2018; Stenstrom et al. 2014). However, among the major industries lacking smart-managed equipment, high-quality meat tenderness based on ageing tenderisation is usually at the expense of long ageing time, sufficient storage space and high energy consumption. Thus, various other effective or supplementary tenderising techniques have been developed based on economic and energy-saving considerations.

\section{Calpain system and tenderising mechanism}

Studies have indicated that endogenous enzyme systems (calpain, caspase, and cathepsin) are mainly responsible for proteolysis in postmortem ageing (Koohmaraie \& Geesink 2006; Shackelford et al. 2001). Among these systems, the calpain system is well established, and its hydrolyzability is affected by the $\mathrm{Ca}^{2+}$ concentration in sarcoplasm, ratio of calpain and calpain inhibitor, $\mathrm{pH}$, temperature, and oxidative environment (e.g., oxygen radicals) (Chen et al. 2014; Geesink et al. 2000; Melody et al. 2004; Piatkov et al. 2014).

The calpain system chiefly comprises calpain and its endogenous inhibitor calpastatin, which are $\mathrm{Ca}^{2+}$-activated proteases (Huff-Lonergan et al. 1996; Koohmaraie 1992). The $\mu$-calpain (mainly bound to myofibrils) and $\mathrm{m}$-calpain (located in the cytosol) are the most characterized isoforms of calpain, whereas the location of their inhibitor, calpastatin, coincides with them (Ilian et al. 2004; Tullio et al. 1999). The $\mathrm{Ca}^{2+}$ concentration required for activation of $\mu$-calpain and $\mathrm{m}$-calpain is different. The $\mathrm{Ca}^{2+}$ level to activate $\mathrm{m}$-calpain is much higher than that of $\mu$ calpain, accompanied by unchanged activity during the ageing process (Koohmaraie \& Geesink 2006). Additionally, these two isoforms differ in their action time in postmortem muscle. The $\mu$-calpain is activated coinciding with the period of postmortem (within 3 days of slaughter) when proteolysis of key myofibrillar proteins takes place (Sensky et al. 1996), accompanied by the occurrence of autolysis within 7 days postmortem (Camou et al. 2007). Nevertheless, m-calpain is not activated in the early stages of postmortem ageing but may play a certain role at the end of ageing tenderisation (Cruzen et al. 2014). Hence, it is generally believed that $\mu$-calpain, rather than $\mathrm{m}$-calpain, mainly participates in ageing tenderisation.

Calpastatin can inhibit the activation of protease hydrolysis as well as the calpain membrane binding capacity and catalytic activity (Huff-Lonergan et al. 2010). After slaughter, the content of calpastatin in muscle will decrease gradually. The speed of degradation or inactivation of calpastatin is related to the expressive proteolysis in muscle. Meanwhile, the increased calpain expression or decreased calpastatin expression will lead to the increase of protease hydrolysis and muscle tenderness. In other words, calpastatin interacts with $\mu-/ \mathrm{m}$-calpain to collectively regulate postmortem tenderness. Notably, numerous protein kinases can phosphorylate the calpain system in postmortem muscles (Wang et al. 2011). Proteins (e.g., troponin) participating in muscle contraction will decrease the calpain degradability to these proteins and change the activity of glycolytic enzymes when undergoing phosphorylation, ultimately influencing the glycolysis process, muscle rigidity and final meat qualities (D'Alessandro et al. 2012; Huang et al. 2012). However, questions regarding whether the phosphorylation of $\mu-/ \mathrm{m}$-calpain and calpastatin will change their activities to alter their influence during tenderising process, and how the phosphorylation of calpastatin intervenes in the inhibition ability of calpain, deserve further in-depth studies. These investigations allow meat scientists to clarify the regulatory mechanism of the calpain system in postmortem muscle and to enrich the corresponding theories of ageing tenderisation.

Calpain can effectively degrade key proteins in myofibrils (e.g., nebulin, titin, troponin- $\mathrm{T}$ and desmin) and degrade the tissue ultrastructure to promote myofibril fragmentation and meat tenderness. The tenderising paths of calpain are shown in Fig. 3 and are summarized in four points: (1) titin, as a very thin filament, can connect thick (myosin) filaments with the Z-disk and generate passive tension to keep the thick filaments centred within the sarcomere. Calpain can effectively weaken the interactions between thick filaments and the Z-disk to fracture the Iband and Z-disk in myofibrils for a looser structure (Tanabe et al. 1994); (2) the degradation of costamere and 


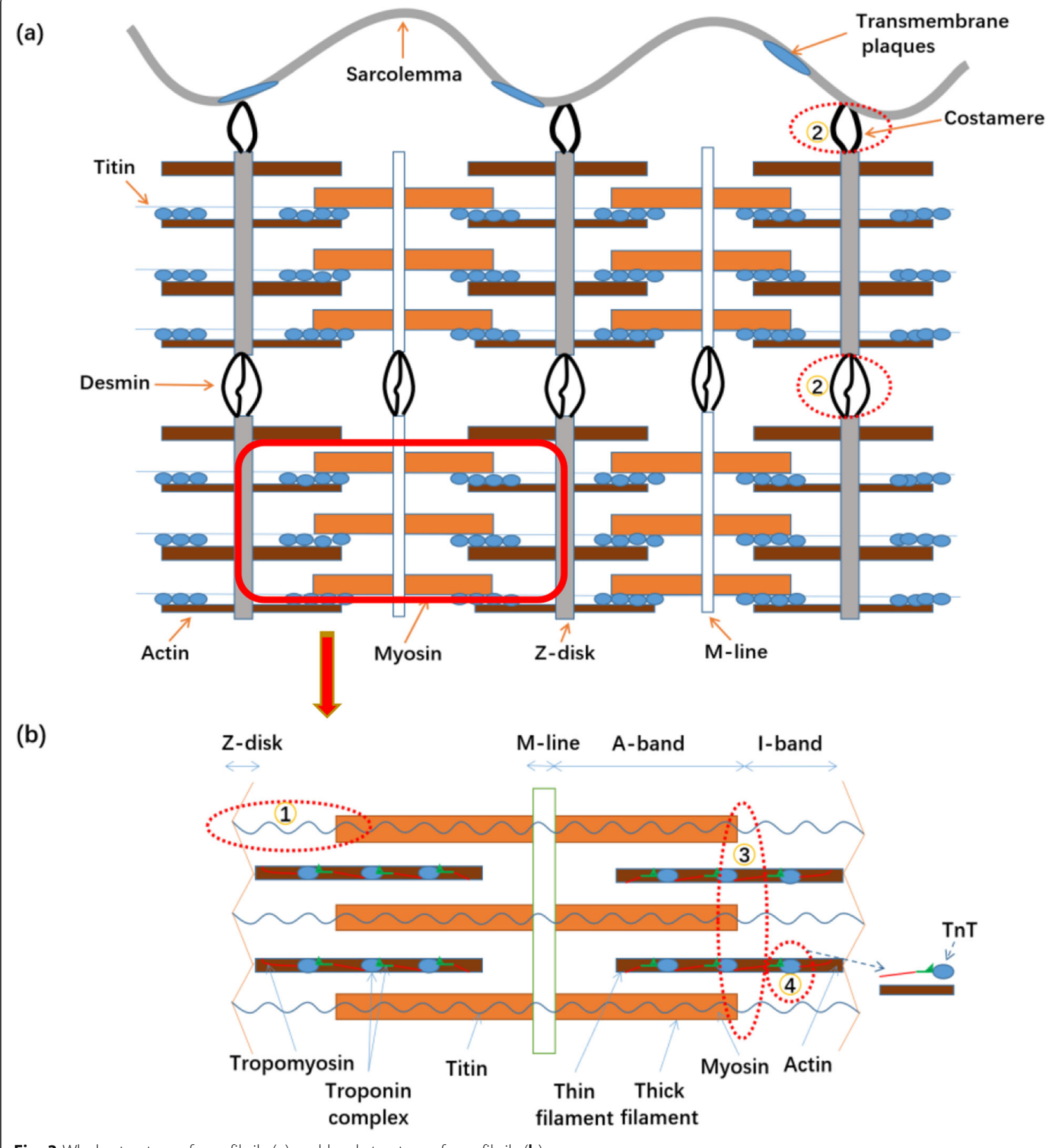

Fig. 3 Whole structure of myofibrils (a) and local structure of myofibrils (b)

desmin induced by calpain can destroy the ordered structure of myofibrils or integrity between myofibrils and peripheral muscles (Uytterhaegen et al. 1994); (3) calpain plays an important role in tropomyosin degradation, and it can weaken the bond between thick and thin filaments. Thus, the interaction between myosin and actin becomes weaker, stimulating the relief of rigidity to improve tenderness (Takahashi et al. 1985); and (4) calpain can degrade troponin- $\mathrm{T}$ (i.e., the tropomyosin-binding subunit) to weaken the structure of thin filaments for better tenderness (Whipple \& Koohmaraie 1992).

\section{Protein biomarkers characterizing postmortem} tenderness

Typically, the methods widely accepted in practice for tenderness evaluation (sensory test, shear force, textural 
analysis) exist the following characteristics: (1) the targeted sample is the cooked meat which can be influenced by heating equipment and cutting size; (2) the results only reflect the meat quality at that time; and (3) these tools are destructive or time-consuming, which are not suitable to determine the biological pathways and to predict the future tenderness. In the past 20 years, the development of proteomics boosts the exploration of biomarkers used to accurately evaluate or predict tenderness for guaranteed meat products based on nondestructive way. Numerous publications have reported the identified biomarkers related to meat tenderness and some relevant biological pathways are depicted in Fig. 4. The main protein biomarkers characterizing tenderness include metabolic enzymes (GAPDH (glyceraldehyde-3phosphate dehydrogenase) and TPI1 (triosephosphate isomerase)) (Ertbjerg \& Puolanne 2017; Huang et al. 2012; Tarze et al. 2007), HSP (HSPB1 (heat shock protein $27 \mathrm{kDa} \mathrm{B} 1$ ) and HSPA1B (heat shock protein $70 \mathrm{kDa}$ 1B)) (Gagaoua et al. 2018; Lomiwes et al., 2014b; Picard et al. 2014), structural proteins (ACTA1 ( $\alpha$-actin) and titin) (Beldarrain et al. 2018), oxidative proteins (PARK7 (parkinson disease protein 7)) (Gagaoua et al. 2015; Malheiros et al. 2019) and FHL1 (four and a half LIM domains 1, involved in cell death and signaling) (Gagaoua et al. 2018; Lee et al. 2015).

GAPDH level is positively associated to sarcomere length and myofibrillar fragmentation index (MFI), and it can trigger the release of Cytc and AIF by combining VDAC-1 proteins (voltage-dependent anion channel-1) in the mitochondrial membrane, thereby inducing apoptosis (Sierra et al. 2012; Tarze et al. 2007). TPI1, another essential enzyme in glycolysis, catalyzes the interconversion of
DHAP (dihydroxyacetone phosphate) and G3P (glyceraldehyde-3-phosphate). These two metabolic enzymes are related to postmortem muscle $\mathrm{pH}$, giving rise to the accumulation of lactic acid and $\mathrm{H}^{+}$(Huang et al. 2012; Ouali et al. 2013). The decreased electrostatic repulsion between myofibres and $\mathrm{pH}$-induced lateral shrinkage that reduces the spacing between thick (myosin) and thin (actin) filaments, thereby alleviating the lateral contraction of muscle fibres and lengthening the longitudinal sarcomeres for improved tenderness (Fig. 4a) (Ertbjerg \& Puolanne 2017). After slaughter, the muscle will suffer the attack of external stressors (e.g., oxidation and temperature) that stimulate the development of apoptosis, and the HSPs (e.g., HSPB1 and HSPA1B) have been reported that their expression levels have positive correlation to meat tenderness (Lomiwes et al. 2014b). The possible mechanism is that they are induced and recruited to fight against the attack by regulating the aggregation of actin and interaction between intermediate filaments (titin), thereby stabilizing myofibrillar integrity (Fig. 4b) (Gagaoua et al, 2018; Lomiwes et al. 2014b; Picard et al. 2014). Titin playing a key role in maintaing the integrity and stability of the myofibril (Tskhovrebova \& Trinick 2010) will undergo partial degradation immediately after slaughter and further degradation takes place during the first $24 \mathrm{~h}$ postmortem (Taylor et al. 1995; Wu et al. 2014). The rupture of myofibrils accelerates dissociation of actomyosin during ageing process, which provides opportunity for ACTA1 to interact with thick myofilament to regulate muscle contraction and tenderness (Fig. 4c) (Beldarrain et al. 2018).

In addition to the above-mentioned structural proteins, some oxidative proteins (e.g., PARK7) will have

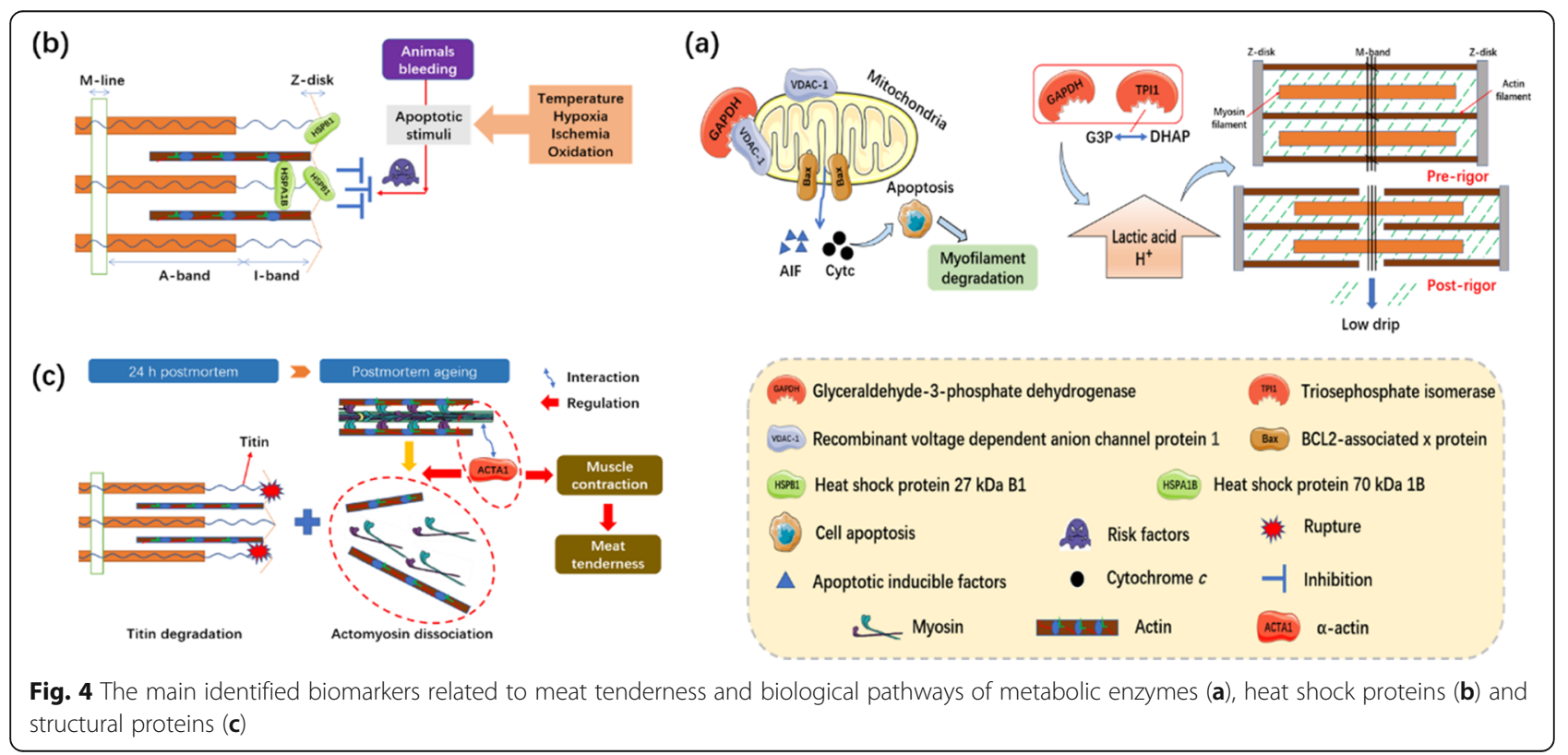


impact on changing the structural or functional properties of proteins and related enzyme activity, intervening in apoptosis and damage of cellular functions (Malheiros et al. 2019). PARK7 proteins mainly affect meat tenderness by altering MP degradation (Gagaoua et al. 2015). However, PARK7 as a quencher for ROS negatively contributes to meat tenderness (Guillemin et al. 2011). FHL1 protein is a cytoskeleton-related protein, which is positively correlated with tenderness (Gagaoua et al. 2018). This may be attributed to FHL1's role in regulating cell proliferation, metabolism and apoptosis (Shathasivam et al. 2010). FHL1 is confined to the Z-disk of skeletal muscle and releases intact $\alpha$-actinin from myofibrils to weaken Z-disk during meat tenderisation (Lee et al. 2015).

Although numerous biomarkers related to meat tenderness have been gradually discovered, their limited accuracy for specific carcass species (e.g., cattle and pigs) and unavailable industrial application deserve much attention. Different muscles in the carcass exist inconsistent tenderness due to the differences in sarcomere length, collagen cross-linking, and postmortem biochemical activities (Veiseth et al. 2004; Warner et al. 2017). Thus, establishing more prediction models based on multidimensional factors (e.g., muscle types, species, sex and age) and developing the associated fast, nondestructive, on-line detection technology for biomarkers are essential. This will exhibit huge potential on generating high-quality meat and economic benefits.

\section{Postmortem techniques to improve meat tenderness}

\section{Enzymatic techniques}

The higher strength of connective tissues or inadequate endogenous protease leads to difficulties in tenderising postmortem meat, and thus muscles in old animals may suffer from substantial toughness. Meat tenderness can be achieved by adding exogenous enzymes through marination, infusion and direct injection (Veiseth et al. 2004). Table 1 summarizes the commonly used exogenous enzymes extracted from different sources (plants, microbes, and animals) and their corresponding functions in meat tenderisation.

Papain, bromelain (Kim \& Taub 1991; Xu et al. 2020), ficin (Maqsood et al. 2018), actinidin (Ha et al. 2012; Wang, Liu, et al. 2016), and zingibain (Cruz et al. 2020; Tsai et al. 2012) are common plant-derived exogenous enzymes, and papain is one of the most widely studied plant proteases. Generally, its sulfhydryl endopeptidase activity can cleave most peptide bonds and disintegrate proteins under different $\mathrm{pH}$ conditions (Abdel-Naeem \& Mohamed 2016; Bekhit et al. 2014; Maqsood et al. 2018). Notably, the concentration and purity of enzymes used in the experiments by different researchers vary, thus it is difficult to achieve a uniform trend in terms of their tenderising effect. Moreover, the cutting method, storage temperature and other interventions influence their tenderising effect. The inactivation temperature of plant proteases (e.g., papain, $90^{\circ} \mathrm{C}$ ) is usually higher than that of microbial proteases, thus the residual activity of plant proteases in meat after cooking may result in overtenderisation. Therefore, the time-temperature combination of cooking, relative ratio of enzyme to substrate, and other factors need to be considered.

Traditional plant proteases have broad specificity, which easily generates undesirable results by indiscriminately disintegrating connective tissues and myofibrillar protein (poor paste texture and flavor). However, microbial proteases (fungal or bacterial sources) can eliminate the risk of over-tenderisation with self-limiting activity and have a strong specificity for target proteins (Ashie et al. 2002). Proteases from fungal sources are active over a broad $\mathrm{pH}$ range and display a moderate denaturation temperature. These proteases have a mild or no effect on MP but manifest good proteolytic activity against both collagen and elastin (Foegeding \& Larick 1986; Sun et al. 2018). Proteases from bacterial sources generally tenderise meat under relatively specific activity and low inactivation temperatures. For example, the alkaline elastase from the Bacillus alkalophilic sp. strain $Y a-B$ has low activity on myofibrils and strong specificity on elastin, thus avoiding over-tenderisation (Yeh et al. 2002). The rapid development of biotechnology and protein purification capability is conducive to producing microorganisms and optimizing the molecular structure of target enzyme without seasonal changes. Compared with plant or microbial protease, few studies have focused on the application of animal proteases for meat tenderisation, possibly due to their low hydrolytic activity towards myofibrillar protein and high developmental cost, but they manifest higher potential to hydrolyze collagen in connective tissues. For instance, proteases (placental and pancreatin) extracted from porcine organs can improve meat tenderness by effectively destroying the Z-disk and $\mathrm{H}$-band to stretch the sarcomere and degrading myosin to loosen the structure of actomyosin (AM) (Phillips et al. 2000; Pietrasik et al. 2010).

The application of exogenous proteases in meat tenderisation requires comprehensive consideration of their source, purity of commercial preparation, safety of effective dosage, consumers' acceptability, sensory quality and cost. Moreover, the addition of exogenous protease needs to reach a balance between selective degradation of muscle structure (i.e., effective reduction in the content of connective tissue, other than the broad degradation to myofibrils) and texture/sensory attributes. Proteolysis induced by exogenous proteases will change the composition, cleavage sites, and digestibility of the 


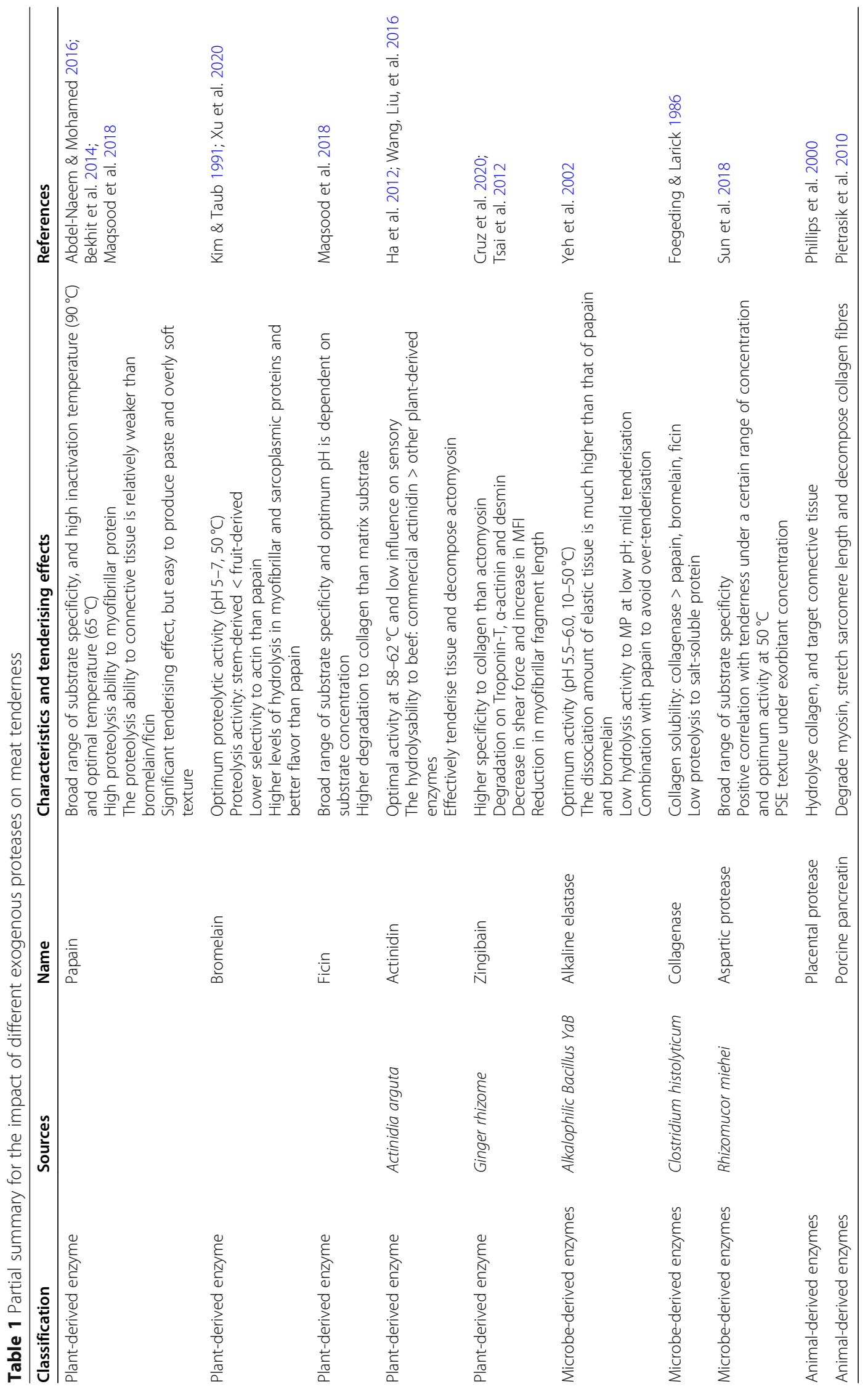


target protein to generate bioactive peptides (Lafarga \& Hayes 2014). However, few studies have correlated enzymatic tenderisation with meat nutrition, a subject that deserves further investigation (Zhao et al. 2020).

\section{Chemical techniques}

Salts (chloride, phosphate, and non-phosphate compounds), organic acids, and commercial preparations, such as amino acids, alginates, and purine nucleotides, among others, are extensively studied or explored. Normally, they generate a desirable outcome that improves meat tenderness through infusion, marination and injection.

\section{Salt tenderisation}

Salts mainly affect the functional properties of meat/protein (e.g., muscle contraction, protein-protein interaction, protein solubility, enzyme activity and protein lattice swelling) as shown in Fig. 5. Chloride bound to myofibres can enhance the electrostatic repulsion between myofibrils, resulting in the swelling of the protein lattice. One key explanation for swelling is the removal of the constraints of one or more transverse structures in myofibrillar protein (possibly bridge, M-line or Z-disk) under the critical concentration (1\%) of salts (Bendall 1954).

Considering the health burden associated with excessive sodium intake, reducing the consumption of dietary sodium from meat products has gained increasing attention. Phosphates can promote the ionic effect and change the $\mathrm{pH}$. These phosphates at lower concentrations can change the potential of protein charge, improve the ionic strength to induce deviation from the isoelectric point and repulsion between charges (Choe et al. 2018). Thus, the space between proteins becomes enlarged, and the meat tissue could retain more water. Compound phosphates can also improve collagen solubility to reduce the cross-linking of collagen in connective tissues, consequently improving meat tenderness. Additionally, polyphosphates can contribute to better tenderness by affecting the dissociation of the actomyosin complex (Shen et al. 2016).

The main function of calcium salt is to increase the $\mathrm{Ca}^{2+}$ concentration in the muscle system and activate the calpain system, leading to MP degradation and rupture of the myofibrillar structure (Li et al. 2017; Wheeler et al. 1991). Calcium activated neutral protease (CANP) and alkaline phosphatase are activated when a high concentration of $\mathrm{Ca}^{2+}$ permeates muscle cells to promote the glycolysis process, lysosomal breakdown, and release proteins in tissue for improved tenderness (Sørheim et al. 2001).

However, most of these compounds are not acceptable to people as excessive intake of $\mathrm{NaCl}, \mathrm{CaCl}_{2}$ and/or

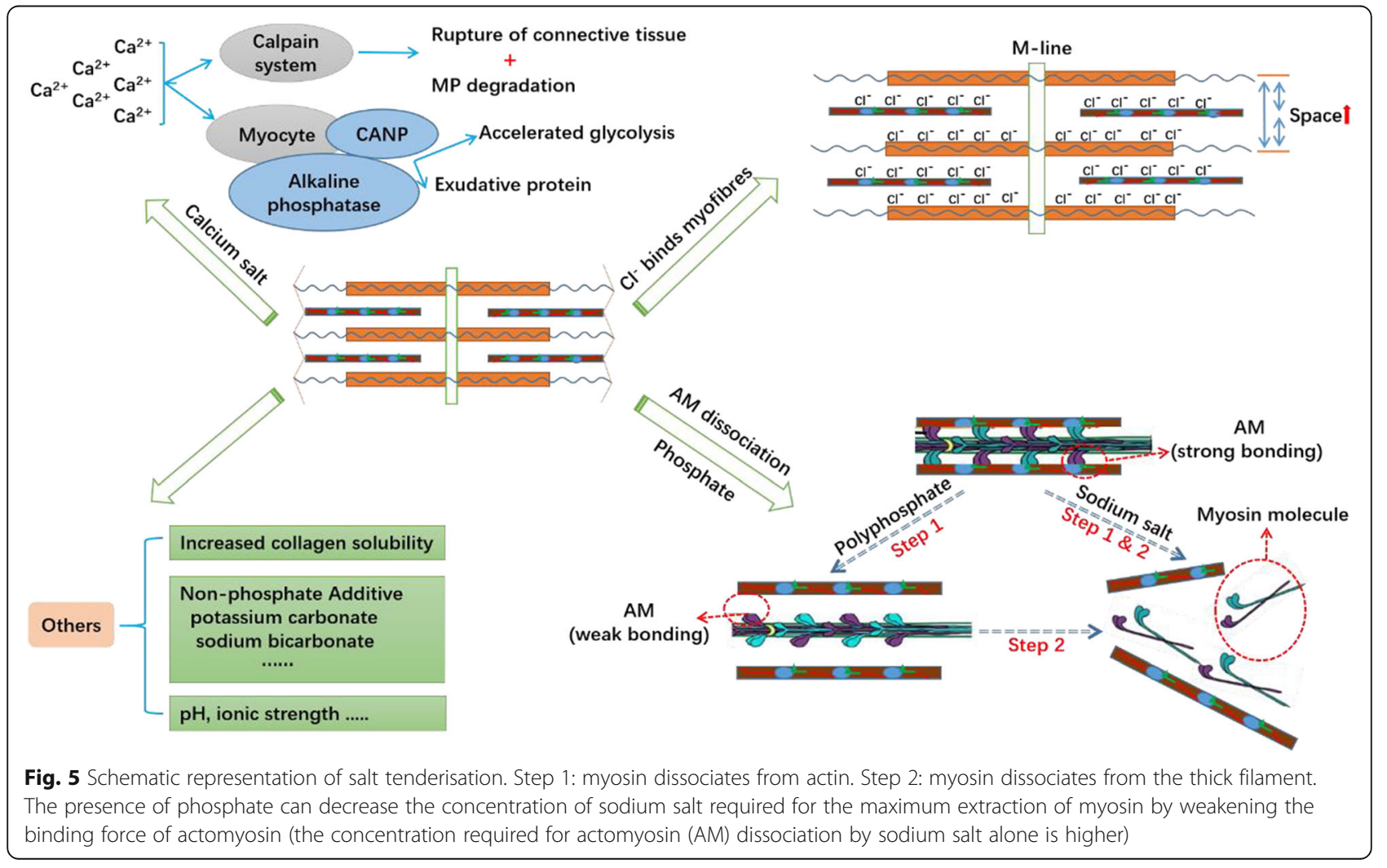


phosphates has potential health risks (e.g., hypertension and coronary heart disease) or may have a bitter taste (Kloss et al. 2015; Zhang et al. 2015). Non-phosphate water-retaining agents (e.g., potassium carbonate and sodium bicarbonate) have similar functions as phosphates (LeMaster et al. 2019; Zou, Shi, et al. 2019). For example, sodium bicarbonate overcomes the concern about superfluous addition of it to the taste of meat products. However, carbonate is generally alkaline, showing corrosive and destructive effects on the structures of protein or myofibrils, thus it is necessary to consider the nutrient loss. In conclusion, the mechanisms of salt tenderisation can be comprehensively understood based on improved muscle WHC, decreased thermal stability of collagen, increased ionic strength for proteinprotein and protein-water interactions and the activation of proteolytic enzymes (e.g., calpain).

\section{Organic acid tenderisation}

Muscle $\mathrm{pH}$ is crucial to the sensory attributes (appearance/color, texture/tenderness and taste) of meat products, which can affect consumers' acceptance. Organic acids (e.g., acetic acid, citric acid, and lactic acid) mainly interfere with the internal environment of muscle to affect meat tenderness (Chang et al. 2010; Ke et al. 2009). The main processing methods are immersion and injection; their corresponding mechanisms are briefly described here. (1) The organic acids can change the muscle $\mathrm{pH}$ and isoelectric point of myofibrillar protein, and the main axis of myofibrils will swell to destroy the related load-bearing substances; (2) organic acids can effectively destroy the structure of meat tissue, and the decreased strength of connective tissue in the perimysium will contribute to reducing the bound myofibrils. Thus, the wider space between myofibrils can retain more water for increased WHC, further improving meat tenderness; (3) proteases (mainly cathepsin) at low $\mathrm{pH}$ can accelerate the tenderising process; and (4) due to the decreased mechanical resistance of muscle and increased collagen solubility, the texture (e.g., chewiness and hardness) of cooked meat treated with organic acids will be significantly improved (Ertbjerg et al. 1999). Considering the slow infiltration of exogenous acids, the immersion treatment needs to reach the full immersion time. By contrast, the injection treatment allows the acid solutions to diffuse quickly in muscles, accelerating the tenderising speed, but the color and shape of meat products will be influenced.

\section{Other exogenous chemical additives}

Reducing the use of phosphates and $\mathrm{NaCl}$ will have negative impacts on the WHC, texture and flavor of meat products (Vasquez Mejia et al. 2019). However, their excessive intake also has adverse influences on health (e.g., cardiovascular disease) (Zheng 2017). Thus, safer chemical additives are evaluated to effectively improve the tenderness of the cooked meat.

Typically, the destruction of myofibrils and dissociation of actomyosin are closely related to improved tenderness (Hopkins \& Thompson 2001; Okitani et al. 2008). Recently, basic amino acids such as L-arginine (Arg), L-lysine (Lys) and L- histidine have attracted increased attention for their ability to decrease shear force and improve WHC by degrading troponin- $\mathrm{T}$ and increasing myosin solubility with higher muscle $\mathrm{pH}$ (Guo et al. 2015; Hayakawa et al. 2010; Zhu et al. 2018a, b). Moreover, Arg displays a more effective tenderising effect than Lys based on its function in promoting actomyosin dissociation by reducing $\mathrm{Ca}^{2+} / \mathrm{Mg}^{2+}$-ATPase activities ( $\mathrm{Li}$ et al. 2019; Zhang et al. 2020). Adenosine $5{ }^{\prime}$-monophosphate (AMP) is an endogenous purine nucleotide that is present in all animals and is involved in metabolism. During postmortem metabolism, ATP hydrolysis will generate hydrolysates to induce irreversible dissociation of actomyosin. Some studies have reported that AMP can effectively dissociate actomyosin into myosin and actin for increased tenderness (Deng et al. 2016; Okitani et al. 2008; Wang et al. 2016). However, it is essential to regulate the marinating conditions (e.g., salt and temperature) when AMP is converted to inosine monophosphate (IMP) by adenosine monophosphate deaminase (AMPD) (Zhu et al. 2018b).

Alginate is an important sources of nutrients and bioactive phytochemicals with increasing acceptance in western diets and are mainly regarded as functional food ingredients (Anderson et al. 1991; Liu et al. 2019). Edible alginates incorporated into processed meat products have been explored in few reports (Trout et al. 2010; Weilin \& Keeton 2006). Alginate addition $(0.7 \%, \mathrm{~m} / \mathrm{m})$ decreases the hardness, cohesiveness, springiness, chewiness and gumminess of the restructured chops (Weilin \& Keeton 2006), and low-fat, precooked, ground beef patties containing alginate are comparable to regular beef patties ( $20 \%$ fat control) regarding yields and textural properties (Trout et al. 2010). As one kind of dietary fibers and polysaccharides, alginate may increase water stability in captured structure of gel network by hydrophobic interactions and hydrogen bonds (Pietrasik \& Janz 2010). Additionally, it can form strong gel or insoluble polymer by cross-linking with $\mathrm{Ca}^{2+}$ in muscle, which generates water barrier to alleviate muscle shrinkage during the heat-induced denaturation (Rhim, 2004; Song et al. 2011). It has been reported that sodium alginate can modify the WHC of myosin gel due to its productive gelling, viscosity-enhancing and stabilizing properties (Yao et al. 2018). Potassium alginate, another alginate, also exhibits synergistic effects on the improved tenderness in combination with ultrasound treatment 
(Shi et al. 2020). Moreover, the optimization of processed meats through salt replacement can reduce the risk of chronic diseases (Vilar et al. 2020).

\section{Traditional physical techniques}

Traditional physical techniques include electrical stimulation, mechanical tenderisation (blade, tumbling, chopping and mincing tenderisation), and contraction-prevention (mainly stretching or tender stretch). Electrical stimulation tenderisation is mostly used in large animals (e.g., cattle, sheep and deer), which can accelerate the degradation speed of ATP and glycolysis, and reduce the $\mathrm{pH}$ to prevent sarcomere shortening (cold contraction) under cold processing (Kim et al. 2014). The changes in $\mathrm{pH} /$ temperature at early postmortem will affect sHSPs activity, proteolysis and muscle tenderness (Contreras-Castillo et al. 2016). Electrical stimulation can also result in the release of lysosomal hydrolase to destroy tissue and accelerate protein hydrolysis to generate tender meat by reducing the ageing time (Channon et al. 2016).

Meat tenderness is closely related to the degree of contraction of muscle during rigor mortis. Therefore, the tender stretching or other stretching technologies (tender cut) are developed to prevent sarcomere shortening by exerting force opposite to the contraction tension of pre-rigor muscles, consequently increasing the myofibrillar fragmentation index of muscle and meat tenderness (Pen et al. 2012). Obviously, these stretching technologies operate based on the relatively accurate control of force or else muscle myofibrils will be overdamaged with undesirable tenderness (Smith et al. 2017). Different from the aforementioned stretching technology, SmartStretch ${ }^{\text {Tw }}$ technology is not limited to intact carcasses. It can reduce the space and energy consumption of the cryogenic chamber for a better tenderising effect by precisely controlling the muscle size and shape (Taylor et al. 2013; Toohey et al. 2012). However, associated studies, especially basic reports on the molecular changes in cut meat during the stretching and shaping process, are insufficient. Moreover, the differences in the sarcomere length and peak shear force in different muscles treated by SmartStretch ${ }^{\mathrm{Tm}}$ have not been well understood. Notably, the degree of contraction of myofibrils changes with the muscle type, which is reflected in glycolysis, temperature and $\mathrm{pH}$ during rigor mortis. Thus, meat scientists need to focus studies on muscle stretching and shaping to obtain relatively consistent results in commercial application. Another effective stretching technique is the Tenderbound system, which is based on the longitudinal forces on meat exerted by the retraction of film under vacuum (Taylor \& Hopkins 2011). This technique is commercially applied in Europe due to its better performance in improving tenderness, saving space, and use of environmentally friendly packaging materials.

Mechanical tenderisation is based on the principle that the rupture of the muscle caused by mechanical force can contribute to improved tenderness. However, meat products treated with this method except the tumbling technique are usually low price due to excessive damage to their appearance or shape. Thus, only the tumbling tenderisation is introduced in the present review. Tumbling is a technique exerting mechanical action on muscle fibre structure and collagen fibres by combining various forms of force (e.g., gravity of meat itself, strong friction and impact forces between the meat and device) with effective moisture enhancement (salt/phosphate) (Arnau et al 2007; Ergezer \& Gokce 2011; Pietrasik \& Shand 2005). Numerous studies have reported that tumbling plays an important role in enhancing the rate of salt diffusion or uniform distribution, cooking yield (increased protein extraction and salt absorption), and improving tenderness (Daudin et al. 2016; Jin et al. 2015). Additionally, tumbling treatment manifests the ability to marinate large quantities and handle muscles with different sizes. Vacuum tumbling is one of the important tumbling forms, which can contribute to the rapid penetration of brine and expansion of muscle fibres due to the difference in internal and external pressure (Bosse et al. 2017). At the same time, the tumbling treatment will result in tissues with a more porous structure. Another application of pressure-transform tumbling can result in better control of over-tenderisation by alternately using vacuum and pressure tumbling (Zhu et al. 2019). Therefore, the overall impact of mechanical force on improving the tenderness of meat pieces may be enhanced.

Although traditional tenderising technologies have obtained successful application and exist widely, they will generate inevitable problems to some degree. For instance, electrical stimulation does not address the problem concerning final tenderness as the tenderness appealing to consumers needs to undergo a post ageing. Tender cut requires more rooms in the chilling chamber, and it is only useful for the limited muscles that undergo the forced stretching. Therefore, they do not completely reduce the time and costs associated with the traditional ageing process. It is necessary to further promote studies on developing new physical tenderisation strategies.

\section{Potential mechanical techniques High pressure processing}

High pressure processing (HPP) is a technology that applies hydrostatic pressure to products through a liquid medium (Simonin et al. 2012). Insights into other meat attributes influenced by HPP are well documented in a book by Guillou et al. (2016), and this part mainly 
focuses on the relationship between the tenderising effect of HPP and postmortem state of muscle in rigor mortis.

In the pre-rigor muscles, the effective tenderising conditions of HPP are generally at $100-235 \mathrm{MPa}$ and $10-35^{\circ} \mathrm{C}$, and the developed tenderness applied in this range is the result of accelerating/stopping glycolysis (Sikes \& Warner 2016). Muscle glycolysis occurs in pre-rigor muscles to maintain ATP production due to postmortem hypoxia, accompanied by the accumulation of lactic acid and decreased muscle $\mathrm{pH}$. High pressure exerted on pre-rigor muscles results in massive destruction of myofibrillar structure and release of calcium ions, accelerating the glycolysis process and promoting the development of rigor mortis and subsequent ageing process (Warner \& Ha 2019). Moreover, it is possible that the denaturation of glycolytic enzymes will occur, inducing stopping of glycolysis and subsequent rising of muscle pHu. It is worth mentioning that there exists a transition point of $\mathrm{pH} 6.1$ between muscle $\mathrm{pHu}$ and tenderness, where a muscle $\mathrm{pHu}$ above 6.1 displays improved tenderness (Purchas 1990; Purchas \& Aungsupakorn 1993). Hence, the HPP tenderising effect in pre-rigor muscles is highly dependent on the ultimate $\mathrm{pH}$ of treated samples. In post-rigor muscles, applying high pressure at low temperature does not improve tenderness in most cases, and it may even increase toughness, but works at high temperature. When the pressure is at the range of $150-400 \mathrm{MPa}$ and the temperature is higher than $50-60^{\circ} \mathrm{C}$, numerous reports show remarkable tenderising results (McArdle et al. 2011; McArdle et al. 2013; Sikes \& Tume 2014).

Conclusion based on the aforementioned studies could be summarized as follows. The application of HPP at low temperature is suitable for pre-rigor muscles, which can be partly attributed to the accelerated ageing time under the relatively low temperature. The application of HPP at high temperature on post-rigor muscles can be considered a potential commercial processing method. Although HPP technology is not merely regarded as an alternative process of traditional sterilization technology, it has received gradual attention in meat tenderisation. However, market limitations such as unstable color, and undesirable visual "done" appearance with increasing pressure exist. Therefore, HPP application in meat products is often considered as a feasible choice for "readyto-eat" meats, but not "fresh food" shelves. HPP technology is unlikely to replace traditional meat tenderising but can be used as an auxiliary method or as a supplement to the existing methods.

\section{Shockwave processing}

Shockwaves (SW) can produce pressure waves of up to $1 \mathrm{GPa}$ in milliseconds and can exert pressure on vacuum-packaged meat through a liquid medium (principally water). The shockwaves extensively studied are explosive shockwave and electrical shockwave, which are generated by explosives and electrical discharges under water, respectively. Its application in food processing is not limited to early sterilization (Wang \& Abe 2015) as many studies have used it to improve meat tenderness (Bolumar et al. 2014; Bowker et al. 2008).

Figure 6 shows the tenderising effects of the two types of shockwave equipment. Muscle contains $75 \%$ moisture, and the shockwave can diffuse in the fluid medium, generating resistance to water to induce the "rupture effect" (Bolumar et al. 2014). Two main mechanisms of meat tenderisation are first destruction of muscle ultrastructure and secondly enhancing proteolysis or accelerating ageing process. Zuckerman et al. (2013) reported that the alveolate structure of endomysium treated by shockwaves was deformed into a loose meshy structure as observed by scanning electron microscope (SEM). Early studies also found that explosive shockwaves can fragment the I-band of the beef longissimus dorsi and induce formation of jagged edges around the Z-disk, indicating that myofibrils underwent physical damage and wider spacing. Moreover, Bowker et al. (2008) reported that shockwaves enhanced the accumulation of a smallmolecular-weight protein fragment $(30 \mathrm{kDa})$ which arose from the TnT degradation that can characterize meat tenderness by western blotting technology. The energy in unit load generated from explosive shockwaves is larger than that of electrical shockwaves, manifesting a better tenderising effect. However, it is difficult to tenderise muscles to a high tender state due to low protease activity, presence of a high proportion of connective tissues, and relatively short sarcomere length (Claus et al. 2001; Zuckerman et al. 2013).

Stringent requirements exist for meat packaging material and limited industrial promotion, which are attributed to the potential safety problems and technical challenges of explosive-dependent technology (e.g., low product acceptability, high construction cost, and poor durability of the equipment). Electrical shockwave technology can compensate for the variation of muscles in different stages by regulating the repeated pulse, optimized frequency, and energy setting. Overall future studies should focus on the development of new shockwaveresistant packaging material, shockwave equipment with better performance, possibly combined with other new technologies.

\section{Ultrasonic processing}

Ultrasound (US) is a non-thermal technology based on acoustic energy, and it has become a research hot-spot for meat scientists in the field of meat tenderisation. The propagation of acoustic waves between high and low pressure generates micro-bubbles that vibrate and grow 


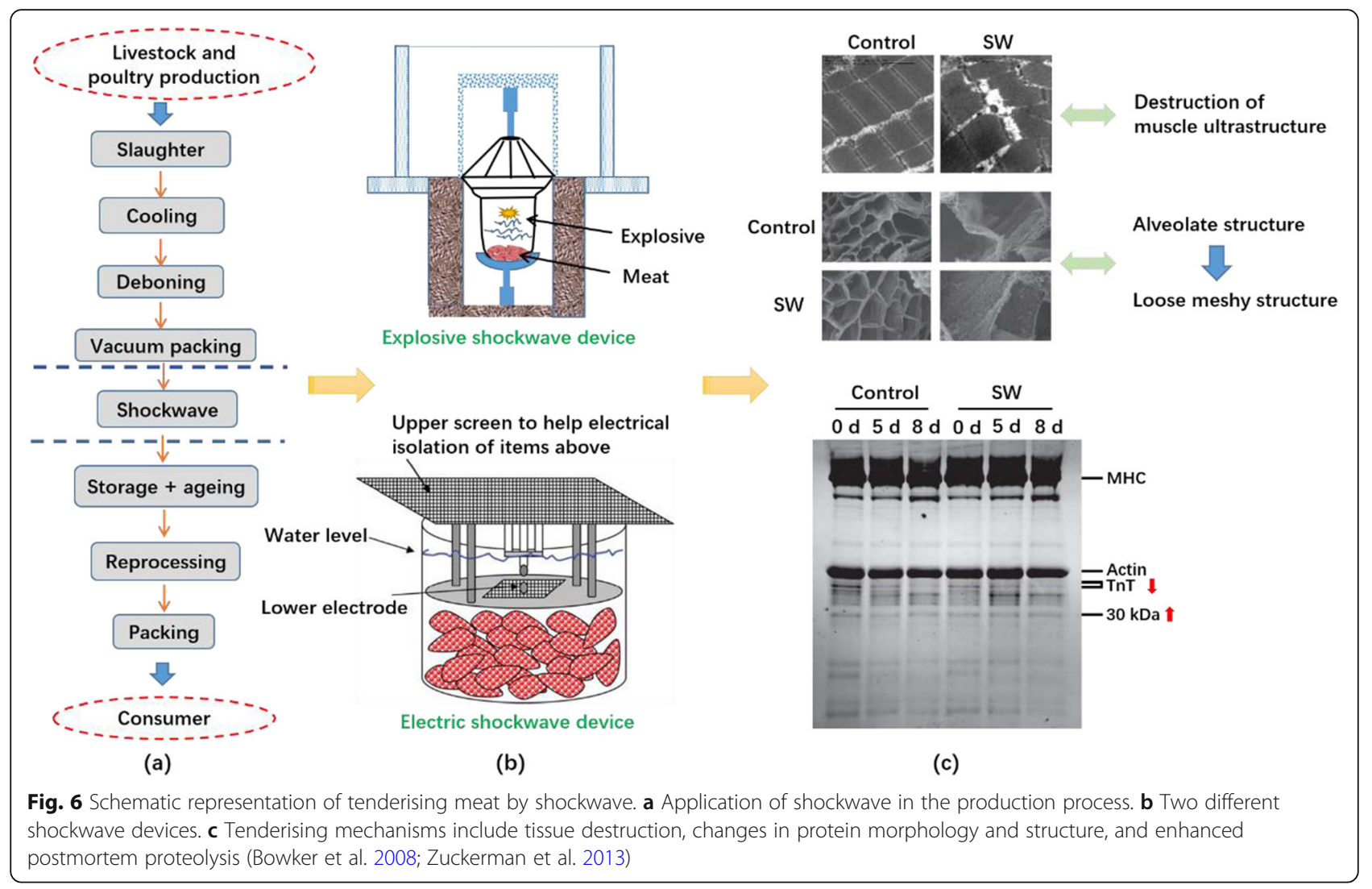

until the bubbles collapse to form a cavitation phenomenon (Fig. 7a). The microjets caused by bubble implosion can cause physical damage (e.g., myofibril fracture) to the meat surface, consequently affecting meat tenderness (Alarcon-Rojo et al. 2019). In addition, cavitation can promote molecular fracture and protein oxidation by inducing the formation of free radicals and accelerating chemical reactions (the cross-linking of disulfide bonds and formation of protein aggregation), thus affecting protein solubility (Kang et al. 2016). Macroscopically, muscles undergoing protein oxidation join tougher; thus, it is essential to reasonably control the time and intensity of ultrasound used for tenderisation. However, it is generally accepted that the lowintensity ultrasound $\left(<10 \mathrm{~W} / \mathrm{cm}^{2}\right)$ has no obvious effect on meat tenderness, especially in the application of ultrasound bath due to the weak cavitation and uncentralized ultrasonic energy (Alves et al. 2013).

The tenderising effects of ultrasound on the postmortem time are different. On the one hand, it is not easy to distinguish ultrasound effects from the muscle undergoing longer postmortem time when the decreased toughness within the action of endogenous protease is considered (Lyng et al. 2007). On the other hand, the effects of ultrasound on pre-rigor muscles mainly focus on evaluating the related protease during rigor onset and the ageing process. Some studies have shown that the ultimate meat tenderness is not improved, although stretch of sarcomere and damage to Z-disk are observed. Numerous studies have suggested that the application of ultrasound on meat should be within $24 \mathrm{~h}$ after slaughter as the muscle $\mathrm{pH}$ reaches $\mathrm{pHu}$ that is needed to reduce the variability in ultrasound tenderisation (Barekat \& Soltanizadeh 2018; Jayasooriya et al. 2007). Ultrasound can activate ATPase, increase the content of sulfhydryl groups, and reduce the formation of aggregates, manifesting more $\beta$-sheet structures and the optimized threedimensional network structure of gelatine for better WHC. Although there exist inconsistent standpoints about the mechanism of ultrasound on water retention (Li, Kang, et al. 2014; Saleem \& Ahmad 2016; Zou et al. 2018), it is generally believed that the appropriate ultrasound parameters can promote the penetration of salts or water-retaining agents, and the synergistic effects indeed enhance the WHC of meat products (Wang et al. 2018; Zou et al. 2019).

A mainstream ultrasound device is shown in Fig. 7b; the tenderising mechanisms of ultrasound can be mainly summarized by considering three aspects: (1) physical destruction of myofibrils and tissue structures (Fig. 7c); (2) increased hydrolysability of proteins during ageing (such as increased release of cathepsin) and rupture of collagen and cell membranes (Fig. 7d); and (3) physicochemical changes of proteins and improved gelling 


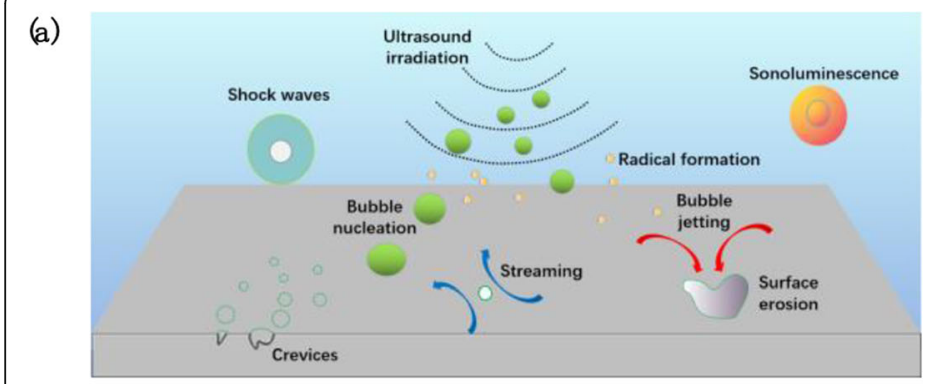

(c)

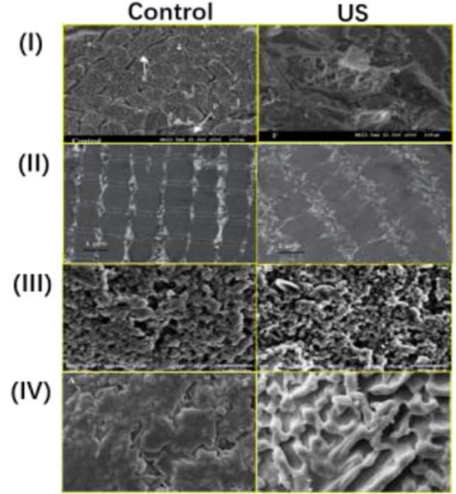

(d)

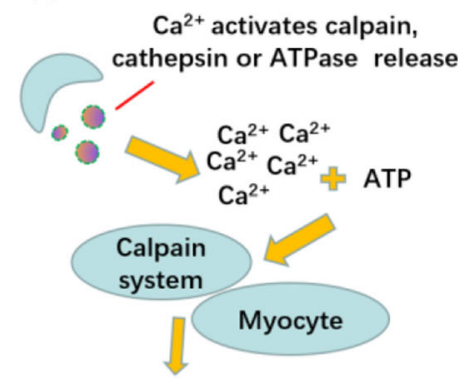

Tissue rupture, protein degradation, glycolysis acceleration

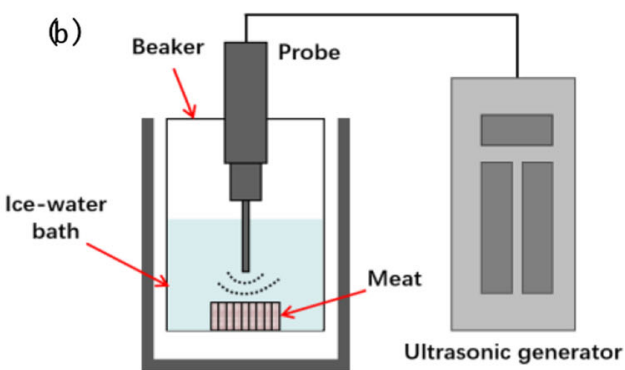

(e)

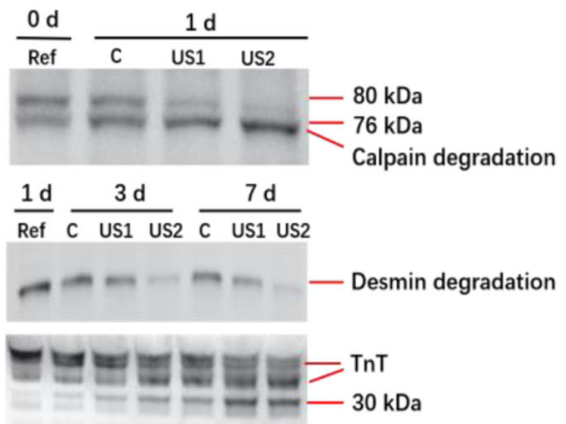

Fig. 7 Schematic representation of ultrasound on tenderising meat. a Ultrasonic effects on meat (Alarcon-Rojo et al. 2019, with modification). b Current classic ultrasound device. c Optimized microstructure of tissue (I), myofibrils (II), protein (III), and gel (IV). d Protease activation. e Protein/ protease degradation (Wang et al. 2018)

properties caused by ultrasound effects (Fig. 7e). Considering that currently conflicting views exist on the tenderising effects (mainly contrasting results), we suggest that ultrasound tenderisation should pay more attention to basic studies, including the evaluation of the microstructure, enzyme activity and ultimate meat tenderness after ultrasound treatment, as well as the optimization of processing parameters (ultrasonic frequency, intensity and time). Due to the complexity of the ultrasound technique, it is necessary to address the specific details concerning the equipment model and experimental parameters used in ultrasound tenderisation to reduce the difficulties in repeatability. Moreover, we suggest that scientists and industries should develop industrially viable ultrasound equipment that demonstrates stable power output, a larger volume, and more efficient and safe properties to satisfy the demand for industrial production.

\section{Pulsed electric field processing}

Pulsed electric field (PEF), a environmentally friendly technology for improving the structure and biological activity of food, can be used for meat tenderisation by forming an electric field between two electrodes using a direct current voltage pulse (Bhat et al. 2019a). Due to the large cell size in meat tissue, the PEF intensity is generally not too high, ranging from 1 to $10 \mathrm{kV} \mathrm{cm}^{-1}$ (Toepfl et al. 2014).

PEF treatment of muscle before ageing can promote meat tenderness by increasing the permeability of cell membranes, promoting the release of $\mathrm{Ca}^{2+}$ and $\mathrm{Ca}^{2+}$-activated protease from cell organelles. The early postmortem activation of calpain-2 in PEF-treated muscles, as well as the increase in calpain activity and proteolysis of desmin and troponin- $\mathrm{T}$ were reported by Bhat et al. (2019b). Additionally, meat tenderisation after postmortem ageing also benefits from protein hydrolysis under PEF treatment. Other factors such as the release of lysosomal cathepsin, accelerated glycolysis induced by the release of $\mathrm{Ca}^{2+}$ in pre-rigor muscle, and the physical destruction of muscle caused by high energy may also contribute to improving tenderness (Bhat et al. 2019a; Warner et al. 2017).

Meat tenderness, to a great extent, depends on the integrity of muscle cells. Different from electrical stimulation and stretching technology, PEF treatment can achieve the irreversible permeability of cell membranes without obvious temperature rise under certain conditions (Kantono et al. 2019). PEF can act on muscles in pre-/post-rigor mortis, but the results so obtained are quite interesting (Table 2). PEF treatment has a remarkable impact on tenderising process, and the inconsistent results on whether PEF can improve the tenderness of 
Table 2 The application of pulsed electric field in different status of muscle

\begin{tabular}{|c|c|c|c|c|}
\hline Muscle status & Muscle studied & PEF parameters & Results & References \\
\hline Pre-rigor & $\begin{array}{l}\text { longissimus Lumborum } \\
\text { (beef) }\end{array}$ & $5,10 \mathrm{kV} \times 20,50,90 \mathrm{~Hz}$ & $\begin{array}{l}\text { Tougher with increasing } \\
\text { intensity }\end{array}$ & Suwandy et al. 2015b \\
\hline Pre-rigor & $\begin{array}{l}\text { longissimus Lumborum } \\
\text { (beef) }\end{array}$ & $\begin{array}{l}\text { Repeat PEF }(1 \times, 2 \times, 3 \times) \\
10 \mathrm{kV}, 90 \mathrm{~Hz}, 20 \mu \mathrm{s}\end{array}$ & $\begin{array}{l}1 \times \text { and } 2 \times \text { PEF had no } \\
\text { tenderising effect } \\
3 \times \text { PEF reduced the } \\
\text { tenderness (TD) }\end{array}$ & Bekhit et al. 2016 \\
\hline Pre-rigor & $\begin{array}{l}\text { Semimembranosus } \\
\text { (beef) }\end{array}$ & $5,10 \mathrm{kV} \times 20,50,90 \mathrm{~Hz}$ & $\begin{array}{l}\text { Improved tenderness } \\
21.6 \% \text { reduction in the shear } \\
\text { force (SF) }\end{array}$ & Suwandy et al. 2015b \\
\hline Pre-rigor & $\begin{array}{l}\text { Semimembranosus } \\
\text { (beef) }\end{array}$ & $\begin{array}{l}\text { Repeat PEF }(1 \times, 2 \times, 3 \times) \\
10 \mathrm{kV}, 90 \mathrm{~Hz}, 20 \mu \mathrm{s}\end{array}$ & $\begin{array}{l}\text { Improved tenderness } \\
3 \times \text { PEF produced the lowest } \\
\text { SF }\end{array}$ & Bekhit et al. 2016 \\
\hline Post-rigor & $\begin{array}{l}\text { longissimus thoracis } \\
\text { (beef) }\end{array}$ & $\begin{array}{l}0.2-0.6 \mathrm{kV} \mathrm{cm}^{-1}, 1-50 \mathrm{~Hz}, 20 \mu \mathrm{s} \\
\text { Ageing time }(1,3 \mathrm{~d})\end{array}$ & $\begin{array}{l}\text { PEF had no influence on the } \\
\text { TD and SF }\end{array}$ & Faridnia et al. 2014 \\
\hline Post-rigor & $\begin{array}{l}\text { Longissimus thoracis et } \\
\text { lumborum } \\
\text { (beef) }\end{array}$ & $\begin{array}{l}1.4 \mathrm{kV} / \mathrm{cm}, 10 \mathrm{~Hz}, 20 \mu \mathrm{s} \\
\text { Ageing time }(2,10,18,26 \mathrm{~d})\end{array}$ & $\begin{array}{l}\text { Ageing time showed a } \\
\text { tendency towards reducing } \\
\text { toughness } \\
\text { PEF did not affect the } \\
\text { tenderising process }\end{array}$ & Arroyo et al. 2015 \\
\hline Post-rigor & $\begin{array}{l}\text { Longissimus Lumborum } \\
\text { (beef) }\end{array}$ & $\begin{array}{l}5,10 \mathrm{kV} \times 20,50,90 \mathrm{~Hz} \\
\text { Ageing tine }(1 \mathrm{~d})\end{array}$ & $\begin{array}{l}19.5 \% \text { reduction in the SF } \\
\text { regardless of the intensity }\end{array}$ & Bekhit et al. 2014 \\
\hline Post-rigor & $\begin{array}{l}\text { Longissimus Lumborum } \\
\text { (beef) }\end{array}$ & $\begin{array}{l}5,10 \mathrm{kV} \times 20,50,90 \mathrm{~Hz} \\
\text { Ageing time }(3,7,14,21 \mathrm{~d})\end{array}$ & $\begin{array}{l}19.0 \% \text { reduction in the SF } \\
\text { regardless of the intensity }\end{array}$ & Suwandy et al. 2015a \\
\hline Post-rigor & $\begin{array}{l}\text { Longissimus Lumborum } \\
\text { (beef) }\end{array}$ & $\begin{array}{l}\text { Repeat PEF }(1 \times, 2 \times, 3 \times) \\
10 \mathrm{kV}, 90 \mathrm{~Hz}, 20 \mu \mathrm{s}\end{array}$ & $\begin{array}{l}\text { Decrease by } 2.5 \mathrm{~N} \text { with every } \\
\text { extra PEF }\end{array}$ & Suwandy et al. 2015c \\
\hline Post-rigor & $\begin{array}{l}\text { Semimembranosus } \\
\text { (beef) }\end{array}$ & $\begin{array}{l}5,10 \mathrm{kV} \times 20,50,90 \mathrm{~Hz} \\
\text { Ageing time }(1,3 \mathrm{~d})\end{array}$ & $\begin{array}{l}\text { Positive correlation between } \\
\text { TD and frequency, and } 19.1 \% \\
\text { reduction in the SF }\end{array}$ & Bekhit et al. 2014 \\
\hline Post-rigor & $\begin{array}{l}\text { Semimembranosus } \\
\text { (beef) }\end{array}$ & $\begin{array}{l}5,10 \mathrm{kV} \times 20,50,90 \mathrm{~Hz} \\
\text { Ageing time }(3,7,14,21 \mathrm{~d})\end{array}$ & $\begin{array}{l}\text { Positive correlation between } \\
\text { TD and frequency, and 19.0\% } \\
\text { reduction in the SF }\end{array}$ & Suwandy et al. 2015a \\
\hline Post-rigor & $\begin{array}{l}\text { Semimembranosus } \\
\text { (beef) }\end{array}$ & $\begin{array}{l}\text { Repeat PEF }(1 \times, 2 \times, 3 \times) \\
10 \mathrm{kV}, 90 \mathrm{~Hz}, 20 \mu \mathrm{s}\end{array}$ & $\begin{array}{l}\text { PEF had no influence on the } \\
\text { TD and SF }\end{array}$ & Suwandy et al. 2015c \\
\hline Post-rigor & $\begin{array}{l}\text { Semitendinosus } \\
\text { (beef) }\end{array}$ & $1.9 \mathrm{kV} / \mathrm{cm}, 65 \mathrm{~Hz}, 20 \mu \mathrm{s}$ & $\begin{array}{l}\text { PEF had no influence on the } \\
\text { TD and SF }\end{array}$ & O'Dowd et al. 2013 \\
\hline Post-rigor & $\begin{array}{l}\text { Breast meat } \\
\text { (turkey) }\end{array}$ & $\begin{array}{l}7.5,10,12.5 \mathrm{kV} \times 10,55,110 \mathrm{~Hz} \\
\text { fresh and frozen-thawed meat } \\
\text { Ageing time }(5 \mathrm{~d})\end{array}$ & $\begin{array}{l}\text { PEF had no influence on the } \\
\text { TD and SF in both fresh and } \\
\text { frozen-thawed meat }\end{array}$ & Arroyo et al. 2015 \\
\hline Post-rigor & $\begin{array}{l}\text { Biceps femoris } \\
\text { (beef) }\end{array}$ & $\begin{array}{l}1.7 \mathrm{kV} / \mathrm{cm}, 50 \mathrm{~Hz}, 20 \mu \mathrm{s} \\
\text { Ageing time }(21 \mathrm{~d})\end{array}$ & $\begin{array}{l}\text { Improved tenderness, } \\
\text { decreased SF }\end{array}$ & Faridnia et al. 2016 \\
\hline Post-rigor & $\begin{array}{l}\text { Biceps femoris \& } \\
\text { semitendinosus } \\
\text { (beef) }\end{array}$ & $\begin{array}{l}0.8-1.1 \mathrm{kV} / \mathrm{cm}, 50 \mathrm{~Hz}, 20 \mu \mathrm{s} \\
\text { fresh and frozen-thawed meat }\end{array}$ & $\begin{array}{l}\text { Improved meat tenderness } \\
\text { and colour } \\
\text { Increased fat oxidation and } \\
\text { saturated fatty acids in frozen- } \\
\text { thawed }\end{array}$ & Kantono et al. 2019 \\
\hline Post-rigor & Shoulder (pork) & $\begin{array}{l}0.5-5 \mathrm{kV} / \mathrm{cm}, 50-1000 \text { pulses, } \\
1-25 \mathrm{~kJ} / \mathrm{kg}\end{array}$ & Increased tenderness & Toepfl 2006 \\
\hline Post-rigor & $\begin{array}{l}\text { Longissimus thoracis et } \\
\text { lumborum (pork) }\end{array}$ & $\begin{array}{l}1.2 \text { or } 2.3 \mathrm{kV} / \mathrm{cm} \times 100 \text { or } 200 \\
\mathrm{~Hz} \times 150 \text { or } 300 \text { pulses }\end{array}$ & No effect & McDonnell et al. 2014 \\
\hline
\end{tabular}

post-rigor muscles also deserve mention. The main contradictions are listed as: (1) whether the muscles treated with high-intensity PEF will obtain appropriate ageing time as ageing tenderisation is a biochemical process (Arroyo, Eslami, et al. 2015; Faridnia et al. 2016; O'Dowd et al. 2013); (2) whether low-intensity PEF is insufficient to induce physical destruction of myofibres since lowintensity PEF probably cannot result in sufficient release of $\mathrm{Ca}^{2+}$ and enzymes from organelles to induce irreversible membrane permeability (Arroyo, Lascorz, et al. 2015; Faridnia et al. 2014); and (3) whether the anatomical and physiological differences in muscles can cause 
different muscles to display frequency-dependent or repeat-dependent characteristics because these differences can affect heat generation, conductivity, myofibre composition and cell membrane characteristics (Bekhit et al. 2014; Suwandy et al. 2015a; Suwandy et al. 2015c). High-intensity PEF may cause a temperature rise due to the ohmic heating. Consequently, the denaturation of proteins and enzymes involved in the tenderising process and increasing temperature will easily produce tougher meat. By contrast, studies have revealed that different muscles in pre-rigor mortis may exhibit opposite results regardless of being treated by single or repeated PEF, which may be attributed to the different effects of PEF on the WHC of these muscles (Bekhit et al. 2016; Suwandy et al. 2015b).

Although limited studies exist concerning the applications of PEF on tenderising meat, it shows potential value. Different types of muscle need to be subjected to different optimal parameters in order to reach improved tenderness. It is necessary to focus on evaluating the potential value of PEF treatment in other different species rather than the meat (e.g., beef) that has been broadly studied. The difference in tenderness caused by different muscles needs additional studies to better understand the mechanisms of PEF treatment on muscle structure and tenderness. Furthermore, the interactive designs between PEF with different intensities and repetitions need to be explored to obtain the desirable sensory properties.

The investigative focus between potential physical interventions and different species is shown in Fig. 8 based on the systematic conclusion from Bhat et al. (2018) and Warner et al. (2017). Obviously, the beef is widely studied due to the more muscle types, tougher texture and higher economic value. The interventions like HPP, SWexplosive and PEF possess higher energy exerting on muscles, thus they are not suitable to be applied in the meat having lower background toughness or undergoing ageing. When applying these interventions, manifold issues (e.g., tenderness, preference of consumer, appearance of meat products) taken into account are indispensable. Additionally, as for the poultry (especially chicken breast meat), other carcass parts are rarely focused on. It must be pointed out that emerging technologies applied in meat processing need to overcome the natural resistance to change. From the perspective of consumers, they will accept a healthier, palatable and safer meat products processed by technologies that are "not invasive". Physical treatments hardly induce changes in meat at a chemical level, consumer information thus must be considered as a crucial aspect in the long term to allow consumers to benefit from technological progress. Several studies focus on increase meat tenderness by combining potential physical techniques with chemical substances based on immersion. For consumers, this will raise more attention and worry about food safety and taste. Thus, more effective parameters of emerging treatments and safer guaranteed additives need to be increasingly standardized to pave on the development of emerging interventions on increased tenderness.

\section{Potential cooking techniques}

Cooking/heat processing can affect sensory attributes and consumer acceptance of meat products by changing the corresponding physicochemical properties and flavor. It is widely accepted that the transverse contraction of myofibres under low-temperature heating is the main reason responsible for moisture loss of meat (Bertram et al. 2005). As heating progresses, the denaturation of collagen and longitudinal contraction of myofibres can result in additional loss of moisture, and the changed

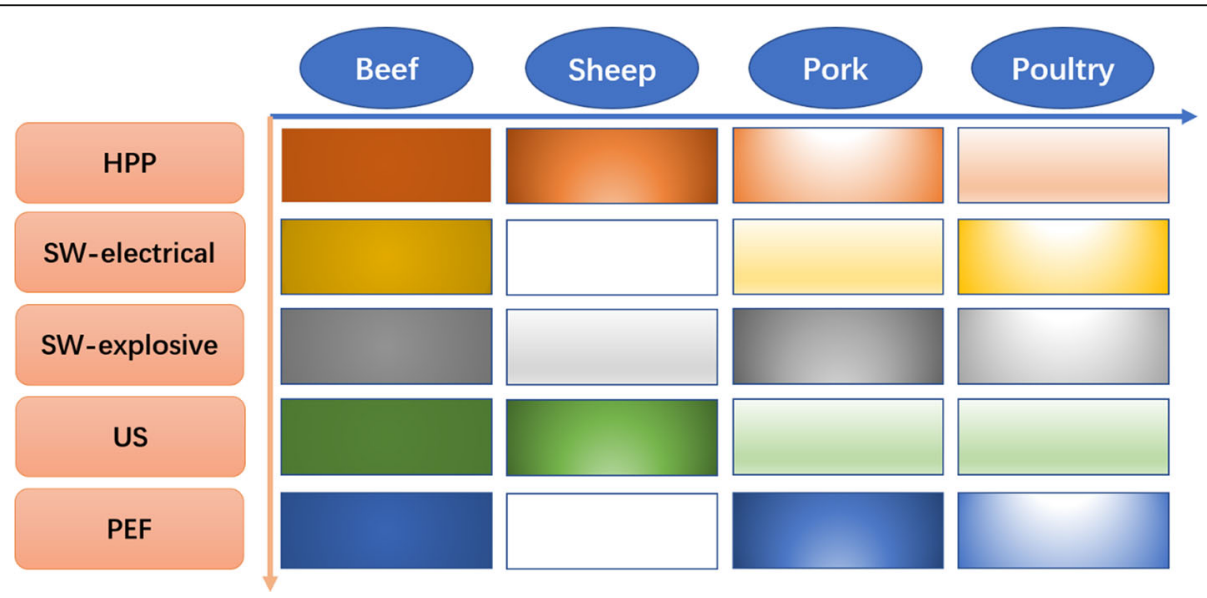

Fig. 8 The investigative focus between emerging physical interventions and different species (Bhat et al. 2018; Warner et al. 2017, with modification). The deeper color of the rectangle is, the wider investigation of the emerging physical intervention is. The white rectangle represents negligible investigation 
structure of myofibrillar protein will lead to tougher meat (Hughes et al. 2014).

\section{Low-temperature long-time cooking}

Low-temperature long-time (LTLT) cooking is a technology that heats food at a constant low temperature ( $\leq$ $60^{\circ} \mathrm{C}$ ) up to few hours or several days. Compared with traditional cooking methods, LTLT cooking can provide meat with uniform and slow penetration rate of heat energy. Thus, myofibre shrinkage is limited, and the increased toughness caused by excessive cooking and high temperature can be avoided (Baldwin 2012). The detailed description about the application of LTLT cooking on meat products is well reviewed by DominguezHernandez et al. (2018), and we mainly emphasize the possible mechanisms of reduction in meat toughness and existing problems.

The mechanism of reduction in toughness under LTLT cooking treatment is not completely clear, but it reveals the following four aspects: (1) LTLT cooking can weaken the myofibre strength and improve the degree of shear fracture by releasing the binding force between myofibres (Christensen et al. 2011); (2) LTLT cooking mainly decreases muscle toughness through collagen dissolution. Although the complete gelation of collagen occurs above $65^{\circ} \mathrm{C}$, Brüggemann et al. (2009) found that a slower heating rate could dissolve major collagen fibres in the epimysium at $59^{\circ} \mathrm{C}$. Moreover, researchers have also proposed that the collagen gelation process in LTLT-treated meat can explain the increasing WHC at $45-60^{\circ} \mathrm{C}$, where the LTLT-cooked meat can undergo continuous collagen degradation to affect the strength of connective tissues (Christensen et al. 2013; Zielbauer et al. 2015); (3) muscle proteases have a certain tenderising effect. For instance, cathepsin displays thermal stability during long-term cooking, destroying the stability of natural collagen and degrading thermally softened collagen into peptides that undergo further hydrolization catalyzed by specific enzymes (Etherington 1976). Hence, proteolysis combined with thermal denaturation in LTLT-cooked meat can produce synergistic effects, manifesting with weaker collagen and decreased toughness (Christensen et al. 2011; Ertbjerg et al. 2012); and (4) heat-induced denaturation of myofibrillar protein can promote protein hydrolysis by changing protein conformation, resulting in the mechanical weakening of muscle structure during long-term heating. Notably, the thermodynamics of myofibrillar protein is more complex than that of collagen as the process of thermal denaturation progresses. However, the hydrolysis of myofibrillar protein mainly occurs in the ageing process, which may have little influence on the tenderness of LTLT-cooked meat.
Considering the current studies on decreasing meat toughness by LTLT cooking technology, we propose the following disadvantages and suggestions: (1) given that the juiciness and tenderness of cooked meat are not completely positively correlated, LTLT setting procedures need to reach a balance between these two attributes (Becker et al. 2016); (2) LTLT-cooked meat is limited in developing flavor due to the lack of volatile aromatic compounds induced by high temperatures; therefore, approaches to modify palatability deserves exploration while simultaneously improving meat tenderness (Roldán et al. 2015); (3) the explanations for LTLTcooked meat tenderness determined by thermodynamics and mechanics may be based on the inference of various factors, and scientists need to further focus on changes in connective tissue components (Christensen et al. 2013; Girard et al. 2012); (4) the muscle ageing process can affect collagen properties, and a large proportion of LTLT-related studies are only based on temperaturetime combinations. Some studies have indicated that muscles, whether undergoing ageing process or not, differ in toughness, even under the same LTLT conditions. In other words, LTLT cooking cannot completely offset the effects of decreased toughness caused by the ageing process (Li, Ma, et al. 2019); therefore, the temperaturetime combination of LTLT cooking needs to be adjusted according to the degree of muscle ageing; (5) LTLTcooked meat may be subject to potential consumer rejection due to microbial safety and original appearance; (6) some studies have indicated that during LTLT cooking the actin in myofibrillar protein will undergo extensive denaturation at temperatures below $60^{\circ} \mathrm{C}$, but this will not significantly increase the meat toughness. Thus, the depth of studies on the denaturation of myofibrillar protein (unfolding and aggregative kinetics) is inferior to that of traditional high-temperature cooking (Zielbauer et al. 2015); (7) some collagen fibres retain their recognisable morphology after a prolonged heating time; thus, the range of collagen dissolution/gelation under LTLT cooking treatment cannot be defined (Sánchez Del Pulgar et al. 2012); and (8) it is beneficial for people to obtain the best cooking scheme for a certain type of muscle according to the characteristics and historical sources of muscles (e.g., freeze-thaw cycles and packaging differences).

Wheeler et al. (1997) once proposed that, although the shear force of the same muscle varied in different studies (possibly attributed to the lack of key information in the instructional protocol), similar results can be obtained if the used equipment is calibrated and the cooking protocol is correctly implemented. Therefore, the LTLT cooking method applied in reduction of meat toughness following the detailed descriptions of the muscle and variable parameters will be effective. Sous vide, one of 
the extensively studied LTLT cooking technologies, is a water bath heating technique for vacuum-packaged meat based on the controlled temperature-time. It can obtain higher uniformity of heat than traditional cooking and directly affects myofibrillar protein and connective tissues. Its difference in decreased toughness is related to the characteristics of raw materials and temperaturetime combination. The mechanisms of decreasing meat toughness by sous vide are similar to the aforementioned LTLT cooking.

\section{Microwave heating}

Another heating technique worth mentioning is microwave cooking. Compared with traditional cooking, microwave heating is more popular among home cooking due to its cleanness, easy-preparation, lower energy consumption, and reserved nutritional characteristics for meat products. However, it also causes uneven heating and lower food quality (Akkarachaneeyakorn et al. 2010). To provide better heating effect and shorter cooking time for lower level of toughness, Young and Kools (2004) and Półtorak et al. (2015) separately developed a surface-auxiliary heating coating with microwave absorption capability, and the combination of convection and low-intensity microwave, but these two methods are not suitable to home cooking due to the inconvenience of operation. Wang et al. (2020) added a microwave susceptor with heat absorption and thermal conductivity at the bottom of the microwave, which can simultaneously realize microwave heating on meat surface and conduction heating at the bottom of meat. The results revealed that this combined form could significantly improve the heating temperature and form a hard shell on the meat surface, thereby reducing moisture loss. Moreover, muscle proteins possess a higher proportion of $\beta$-sheet structures, promoting more water to be firmly grasped in the protein gel for better tenderness. Additionally, it can enhance the retention of flavor, reduce cooking time or cooking loss in order to decrease meat toughness by pre-marination.

\section{Combination techniques}

Regarding intervention technology, the abovementioned potential physical technologies mainly achieve favorable tenderisation through physical disintegration of muscle structure, enhancement of proteolysis, acceleration of the ageing process and promotion of denaturation or dissolution of muscle-related proteins. It is necessary to continuously appeal to the preferences of different carcass muscles, markets (food service industry, fresh products, exports), and consumer groups to optimally utilize these potential physical tenderising technologies.

Among the techniques of meat tenderisation, ageing is regarded as the best way to modify meat texture based on its complex biochemical metabolism and endogenous enzyme systems. Other effective interventions are often designed to adjust the modification of the ageing process to obtain more economical effects and preference or satisfaction of people. Therefore, more advanced techniques are used to combine ageing or other interventions to make the best use of the combined tenderising effects. For instance, ultrasound-assisted ageing can increase muscle $\mathrm{pH}$ (neutral $\mathrm{pH}$ ) to induce higher calpain activity and intervene the early glycolysis of ageing by damaging the cell structures and changing protein conformation (Got et al. 1999; Yeung \& Huang 2017). Moreover, the $\mu$-calpain in neutral $\mathrm{pH}$ muscle displays sufficient proteolytic activity to degrade MP and regulate some structural proteins during the ageing for acceptable tenderness (Kim et al. 2008; Wang et al. 2018). The cavitation effect that ultrasound exerts on muscle can damage mitochondria to initiate apoptosis, and the activated calpains are responsible for cellular rupture and final apoptosis (Yu et al. 2013).

In addition, other scientists have explored different types of ultrasound-assisted technologies (e.g., marination, freeze/thaw, and cooking processing) based on ultrasoud effects (Barekat \& Soltanizadeh, 2018; Shi et al. 2020; Zhang et al. 2018; Zou et al. 2019). The use of exogenous proteases is often combined with ultrasound treatment to decrease the dosage of proteases in meat products. Nevertheless, the flavor, color and lustre of the meat products change dramatically after enzyme treatment, and this combined method may require careful monitoring to avoid over-tenderisation ( $\mathrm{Fu}$ et al. 2019; Fu et al. 2020). Thus, it is necessary to investigate safer ultrasound-assisted enzyme processing to achieve the transformation of technical productivity.

The potential physical techniques principally provide an opportunity for the use of chemical additives by mechanical destruction/fracture of whole tissue to exert their unique/specific functions on myofibrils or protein. Apart from the increased tenderness with better texture, these techniques can be seen as effective salt reduction strategies through pre-treatment or combined synergistic effects, and they have been well documented by Wang et al. (2013). For instance, PEF pre-treatment allows direct reduction of salt $(\mathrm{NaCl})$ without any adverse effect on sensory quality, lipid oxidation as well as microbial stability of products (Inguglia et al. 2017). The results indicate that PEF treatment can improve salt diffusion and sodium delivery, leading to better perception during chewing. PEF could be a novel method to produce healthier meat products with a lower sodium content (Bhat et al. 2020).

In the early postmortem stage, electrical stimulation (ES) is usually used to prevent cold shortening for extra loss and accelerated postmortem metabolism for better 
tenderness and flavor. ES affects the whole carcass with the decreased variability of tenderisation, but it cannot produce the same effect on different muscles in the same animal. Tender stretching (TS) varies in its effect depending on which muscles are stretched. Thus, the combined application of TS with ES on the different muscle types during processing is recommended to maximize meat tenderness (Biffin et al. 2018; Biffin et al. 2020).

Sous vide, as a novel style of cooking, is usually designed as a combination of time and temperature. The degradation in the strength of intramuscular connective tissue (IMCT) can significantly reduce meat toughness after LTLT treatment (Christensen et al. 2013). Moreover, it is widely accepted that postmortem ageing can effectively degrade IMCT and reduce the strength of raw IMCT (Nishimura 2015; Stanton \& Light 1988). Some studies have indicated that muscles, undergoing ageing process or not, differ in toughness, even under the same LTLT conditions (Li et al. 2019). In other words, the temperature-time combination of LTLT cooking also needs to be adjusted according to the degree of muscle ageing (Purslow 2018). Therefore, the combination intervention of sous vide and ageing may produce more tender meat compared with traditional cooking. However, how the IMCT of meat treated with this combination influences toughness when being reheated by traditional cooking is unknown, as the insoluble collagen in IMCT clearly contributes most to meat toughness under the condition of high temperature of cooking. Additionally, some safety concerns must be noted. For instance, the injection of exogenous protease is the method frequently used to reduce the temperature and time during sous vide for tough meat cuts (Zhu et al. 2018a, b). However, the question arises as to whether these proteases with high inactivation temperatures are inactivated during the initial treatment, subsequently resulting in over tenderisation when being reheated. Modern cooking methods may be beneficial to reduce the incidence of undesirable compound formation, but the synergistic effect on flavor is unclear or has not been extensively studied when combined with other additives.

\section{Prospects}

Future trends in the development of new tenderising technologies and the questions deserving further consideration by the meat processing industry are as follows: (1) Develop more intelligent and efficiency-integrated equipment to tenderise meat, and establish non-destructive evaluation models or database for predicting postmortem tenderness; (2) Develop newfashioned equipments or methods for strecthing and shaping to enhance tenderness by reducing long term storage and ageing based on existing flexible technologies (SmartStretch ${ }^{\mathrm{Tm}} /$ Smartshape $^{\mathrm{Tm}}$ and Tenderbound); (3) Adjust the techniques according to the targeted market (food service industry, fresh products or exports) and the preferences of different consumer groups; (4) Focus, at the same time, on the basic research and detailed descriptions of techniques to reduce difficulties in repeatability; (5) Provide more reliable explanations for combined technologies, in the case where indefinite or additive effects of tenderisation occur; (6) Avoid tenderising meat by merely combining with potential technologies as they normally generate a tenderising effect of " $1+$ $1>2$ " in most cases; (7) Advocate for the investigation of more economical, more accessible, and easier operating technologies for consumers; and (8) pay more attention to the cheap, poor-palatable but nutrient-rich meats, and maximize their value for different groups.

\section{Conclusion}

This review systematically introduces the relationship of ageing tenderisation and calpain system, tenderising techniques and corresponding mechanisms of postmortem meat. To summarize, the calpain system plays a key role in the degradation of structural proteins, destruction of myofibrils, and activation of endogenous proteases to regulate proteolysis, glycolysis, metabolism and the ageing process. Muscle ageing is the main process for improved tenderness that is mediated by multiple mechanisms including the calpain system, cell apoptosis, protein S-nitrosylation/phosphorylation and other biochemical activities (e.g., oxidative stress and sHSPs). The drawbacks of ageing tenderisation (time requirement, larger storage space and higher energy consumption) contribute to the development of other potential tenderising interventions. Additionally, different aspects of tenderising techniques (exogenous enzyme, chemistry, physics and combined methods) are discussed in detail. Among these techniques, the potential physical interventions for tenderisation are mainly discussed in terms of their principles, tenderising mechanisms, existing questions and suggestions. These potential physical techniques can provide the meat industry with a more favorable economical effect through the deeper investigation and broad combination with other effective interventions. Particularly, innovations of cooking (sous vide and microwave) suitable for home cooking are recommended to prepare relatively tender meat due to their convenience and easy operating characteristics.

\section{Abbreviations}

IMCT: Intramuscular connective tissue; SR: Sarcoplasmic reticulum; WHC: Water-holding capacity; ROS: Reactive oxygen species;

Cytc: Cytochrome c; AIF: Apoptosis-inducing factor; HSP: Heat shock protein; SHSPs: Small heat shock proteins; PHu: Ultimate pH; MP: Myofibrillar protein; GAPDH: Glyceraldehyde-3-phosphate dehydrogenase; TPI1: Triosephosphate isomerase; HSPB1: Heat shock protein $27 \mathrm{kDa}$ B1; HSPA1B: Heat shock protein 70 kDa 1B; ACTA1: a-actin; PARK7: Parkinson disease protein 7; FHL1: Four 
and a half LIM domains 1; MFI: Myofibrillar fragmentation index; VDAC1: Voltage-dependent anion channel-1; DHAP: Dihydroxyacetone phosphate; G3P: Glyceraldehyde-3-phosphate; AM: Actomyosin; CANP: Calcium activated neutral protease; AMP: Adenosine 5'-monophosphate; IMP: Inosine monophosphate; AMPD: Adenosine monophosphate deaminase; HPP: High pressure processing; SW: Shockwave; SEM: Scanning electron microscope; US: Ultrasound; PEF: Pulsed electric field; LTLT: Low-temperature long-time; ES: Electrical stimulation; TS: Tender stretching; SF: Shear force;

TD: Tenderness; TnT: Troponin-T

\section{Acknowledgements}

The authors acknowledge the staff of Jiangsu Academy of Agricultural Sciences for extending all necessary facilities during implementation of the study. Thanks to Ms. Yaqian Zhang for her support and encouragement.

\section{Authors' contributions}

HS, YZ and DW contributed to all sections and writing of the article. FS and JW contributed to valuable suggestion of writing. $\mathrm{YH}$ and $\mathrm{WX}$ contributed to technical support. All authors gave approval of the final version to be submitted.

\section{Funding}

This work was supported by the China Agriculture Research System (CARS41), National Natural Science Foundation of China (31901612) and Agricultural Science and Technology Innovation Fund Projects of Jiangsu Province (CX (18)1006)

\section{Availability of data and materials}

All data generated or analyzed during this study are included in this published article.

\section{Declarations}

\section{Ethics approval and consent to participate}

No applicable. The article dose not include animal or human experiments.

\section{Consent for publication}

Neither the article nor portions of it have been previously published elsewhere.

The manuscript is not under consideration for publication in another journals, and will not be submitted elsewhere until the journal Food Production, Processing and Nutrition (FPPN) editorial process is completed. All authors consent to the publication of the manuscript in FPPN, should the article be accepted by the Editor-in-chief upon of the refereeing process.

\section{Competing interests}

Author Dr. Daoying Wang is a member of Editorial Board of Food Production, Processing and Nutrition and he was not involved in the journal's review of, or decisions related to thismanuscript.

\section{Author details}

${ }^{1}$ Institute of Agricultural Products Processing, Jiangsu Academy of Agricultural Sciences, Nanjing 210014, People's Republic of China. ${ }^{2}$ Department of Biochemistry, Memorial University of Newfoundland, A1B3X9, St. John's, NL, Canada. ${ }^{3}$ School of Food and Biological Engineering, Shanx University of Science and Technology, Xi'an 710021, People's Republic of China.

Received: 1 February 2021 Accepted: 13 May 2021

Published online: 22 July 2021

\section{References}

Abdel-Naeem, H. H., \& Mohamed, H. M. (2016). Improving the physico-chemical and sensory characteristics of camel meat burger patties using ginger extract and papain. Meat Science, 118, 52-60.

Akkarachaneeyakorn, S., Laguerre, J. C., Tattiyakul, J., Neugnot, B., Boivin, P., Morales, F. J., et al. (2010). Optimization of combined microwave-hot ai roasting of malt based on energy consumption and neo-formed contaminants content. Journal of Food Science, 75(4), 201-207.
Alarcon-Rojo, A. D., Carrillo-Lopez, L. M., Reyes-Villagrana, R., Huerta-Jimenez, M., \& Garcia-Galicia, I. A. (2019). Ultrasound and meat quality: A review. Ultrasonics Sonochemistry, 55, 369-382.

Al-Hilphy, A. R., Al-Temimi, A. B., Al Rubaiy, H. H. M., Anand, U., Delgado-Pando, G. \& Lakhssassi, N. (2020). Ultrasound applications in poultry meat processing: A systematic review. Journal of Food Science, 85(5), 1386-1396.

Alves, L. d. L., Cichoski, A. J., Barin, J. S., Rampelotto, C., \& Durante, E. C. (2013). O ultrassom no amaciamento de carnes. Ciência Rural, 43(8), 1522-1528.

Anderson, D., Brydon, W. G., Eastwood, M. A., \& Sedgwick, D. M. (1991). Dietary effects of sodium alginate in humans. Food Additives and Contaminants, 8(3), $237-248$

Arnau, J., Serra, X., Comaposada, J., Gou, P., \& Garriga, M. (2007). Technologies to shorten the drying period of dry-cured meat products. Meat Science, 77, 8189.

Arroyo, C., Eslami, S., Brunton, N. P., Arimi, J. M., Noci, F., \& Lyng, J. G. (2015). An assessment of the impact of pulsed electric fields processing factors on oxidation, color, texture, and sensory attributes of Turkey breast meat. Poultry Science, 94(5), 1088-1095

Arroyo, C., Lascorz, D., O'Dowd, L., Noci, F., Arimi, J., \& Lyng, J. G. (2015). Effect of pulsed electric field treatments at various stages during conditioning on quality attributes of beef longissimus thoracis et lumborum muscle. Meat Science, 99, 52-59.

Ashie, I. N. A., Sorensen, T. L., \& Nielsen, P. M. (2002). Effects of papain and a microbial enzyme on meat proteins and beef tenderness. Journal of Food Science, 67(6), 2138-2142

Ba, H. V., Reddy, B. V., \& Hwang, I. (2015). Role of calpastatin in the regulation of mRNA expression of calpain, caspase, and heat shock protein systems in bovine muscle satellite cells. In Vitro Cellular \& Developmental Biology Animal, 51, 447-454.

Baldwin, D. E. (2012). Sous vide cooking: A review. International Journal of Gastronomy and Food Science, 1(1), 15-30.

Barekat, S., \& Soltanizadeh, N. (2018). Effects of ultrasound on microstructure and enzyme penetration in beef longissimus lumborum muscle. Food and Bioprocess Technology, 11, 680-693.

Becker, A., Boulaaba, A., Pingen, S., Krischek, C., \& Klein, G. (2016). Low temperature cooking of pork meat - physicochemical and sensory aspects. Meat Science, 118, 82-88.

Bekhit, A. E.-D. A., Hopkins, D. L., Geesink, G., Bekhit, A. A., \& Franks, P. (2014). Exogenous proteases for meat tenderization. Critical Reviews in Food Science and Nutrition, 54(8), 1012-1031.

Bekhit, A. E.-D. A., Suwandy, V., Carne, A., van de Ven, R., \& Hopkins, D. L. (2016). Effect of repeated pulsed electric field treatment on the quality of hot-boned beef loins and topsides. Meat Science, 111, 139-146.

Bekhit, A. E.-D. A., van de Ven, R., Suwandy, V., Fahri, F., \& Hopkins, D. L. (2014). Effect of pulsed electric field treatment on cold-boned muscles of different potential tenderness. Food and Bioprocess Technology, 7(11), 3136-3146.

Beldarrain, L. R., Aldai, N., Picard, B., Sentandreu, E., Navarro, J. L., \& Sentandreu, M. A. (2018). Use of liquid isoelectric focusing (OFFGEL) on the discovery of meat tenderness biomarkers. Journal of Proteomics, 183, 25-33.

Bendall, J. R. (1954). The swelling effect of polyphosphates on meat. Journal of the Science of Food and Agriculture, 5(10), 468-475.

Bertram, H. C., Aaslyng, M. D., \& Andersen, H. J. (2005). Elucidation of the relationship between cooking temperature, water distribution and sensory attributes of pork - a combined NMR and sensory study. Meat Science, 70(1), 75-81.

Bhat, Z. F., Morton, J. D., Mason, S. L., \& Bekhit, A. E.-D. A. (2018). Applied and emerging methods for meat tenderization: A comparative perspective. Comprehensive Reviews in Food Science and Food Safety, 17(4), 841-859.

Bhat, Z. F., Morton, J. D., Mason, S. L., \& Bekhit, A. E.-D. A. (2019a). Current and future prospects for the use of pulsed electric field in the meat industry. Critical Reviews in Food Science and Nutrition, 59(10), 1660-1674.

Bhat, Z. F., Morton, J. D., Mason, S. L., \& Bekhit, A. E.-D. A. (2019b). Pulsed electric field operates enzymatically by causing early activation of calpains in beef during ageing. Meat Science, 153, 144-151.

Bhat, Z. F., Morton, J. D., Mason, S. L., \& Bekhit, A. E.-D. A. (2020). The application of pulsed electric field as a sodium reducing strategy for meat products. Food Chemistry, 306, 125622

Biffin, T. E., Smith, M. A., Bush, R. D., Collins, D., \& Hopkins, D. L. (2018). The effect of combining tenderstretching and electrical stimulation on alpaca (Vicugna pacos) meat tenderness and eating quality. Meat Science, 145, 127-136. 
Biffin, T. E., Smith, M. A., Bush, R. D., Morris, S., \& Hopkins, D. L. (2020). The effect of whole carcase medium voltage electrical stimulation, tenderstretching and longissimus infusion with actinidin on alpaca meat quality. Meat Science, 164, 108107.

Bolumar, T., Bindrich, U., Toepfl, S., Toldra, F., \& Heinz, V. (2014). Effect of electrohydraulic shockwave treatment on tenderness, muscle cathepsin and peptidase activities and microstructure of beef loin steaks from Holstein young bulls. Meat Science, 98, 759-765.

Bosse, R., Thiermann, N., Gibis, M., Schmidt, H., \& Weiss, J. (2017). Effect of mechanical curing treatments on particle distribution to simulate non-motile bacteria migration in cured raw ham. Journal of Food Engineering, 194, 58-66.

Bowker, B. C., Fahrenholz, T. M., Paroczay, E. W., Eastridge, J. S., \& Solomon, M. B. (2008). Effect of hydrodynamic pressure processing and aging on the tenderness and myofibrillar proteins of beef strip loins. Journal of Muscle Foods, 19, 74-97.

Brüggemann, D. A., Brewer, J., Risbo, J., \& Bagatolli, L. (2009). Second harmonic generation microscopy: A tool for spatially and temporally resolved studies of heat induced structural changes in meat. Food Biophysics, 5(1), 1-8.

Camou, J. P., Marchello, J. A., Thompson, V. F., Mares, S. W., \& Goll, D. E. (2007). Effect of postmortem storage on activity of $\mu$ - and $m$-calpain in five bovine muscles. Journal of Animal Science, 85(10), 2670-2681.

Cao, J., Zhou, G., Liu, Y., Liao, G., Zhang, Q., Ye, K., et al. (2014). Activation of caspase- 9 and its influencing factors in beef during conditioning. Animal, 8(3), 504-509.

Chang, H. J., Wang, Q., Zhou, G. H., Xu, X. L., \& Li, C. B. (2010). Influence of weak organic acids and sodium chloride marination on characteristics of connective tissue collagen and textural properties of beef semitendinosus muscle. Journal of Texture Studies, 41(3), 279-301.

Channon, H. A., Hamilton, A. J., D'Souza, D. N., \& Dunshea, F. R. (2016). Estimating the impact of various pathway parameters on tenderness, flavour and juiciness of pork using Monte Carlo simulation methods. Meat Science, 116, 58-66.

Chen, C., Zhang, J. Y., Guo, Z. B., Shi, X. X., Zhang, Y. B., Zhang, L., et al. (2020). Effect of oxidative stress on AlF-mediated apoptosis and bovine muscle tenderness during postmortem aging. Journal of Food Science, 85, 77-85.

Chen, Q. Q., Huang, J. C., Huang, F., Huang, M., \& Zhou, G. H. (2014). Influence of oxidation on the susceptibility of purified desmin to degradation by $\mu-$ calpain, caspase-3 and -6. Food Chemistry, 150, 220-226.

Choe, J., Lee, J., Jo, K., Jo, C., Song, M., \& Jung, S. (2018). Application of winter mushroom powder as an alternative to phosphates in emulsion-type sausages. Meat Science, 143, 114-118.

Christensen, L., Ertbjerg, P., Aaslyng, M. D., \& Christensen, M. (2011). Effect of prolonged heat treatment from $48{ }^{\circ} \mathrm{C}$ to $63{ }^{\circ} \mathrm{C}$ on toughness, cooking loss and color of pork. Meat Science, 88(2), 280-285.

Christensen, L., Ertbjerg, P., Loje, H., Risbo, J., van den Berg, F. W., \& Christensen, M. (2013). Relationship between meat toughness and properties of connective tissue from cows and young bulls heat treated at low temperatures for prolonged times. Meat Science, 93(4), 787-795.

Claus, J. R., Schilling, J. K., Marriott, N. G., Duncan, S. E., Solomon, M. B., \& Wang, H. (2001). Tenderization of chicken and Turkey breasts with electrically produced hydrodynamic shockwaves. Meat Science, 58(3), 283-286.

Contreras-Castillo, C. J., Lomiwes, D., Wu, G., Frost, D., \& Farouk, M. M. (2016). The effect of electrical stimulation on post mortem myofibrillar protein degradation and small heat shock protein kinetics in bull beef. Meat Science, $113,65-72$

Cramer, T., Penick, M. L., Waddell, J. N., Bidwell, C. A., \& Kim, Y. H. B. (2018). A new insight into meat toughness of callipyge lamb loins - the relevance of antiapoptotic systems to decreased proteolysis. Meat Science, 140, 66-71.

Cruz, P. L., Panno, P. H. C., Giannotti, J. D. G., de Carvalho, R. V., \& Roberto, C. D. (2020). Effect of proteases from ginger rhizome on the fragmentation of myofibrils and tenderness of chicken breast. LWT - Food Science and Technology, 120, 108921.

Cruzen, S. M., Paulino, P. V., Lonergan, S. M., \& Huff-Lonergan, E. (2014). Postmortem proteolysis in three muscles from growing and mature beef cattle. Meat Science, 96(2), 854-861

D’Alessandro, A., Rinalducci, S., Marrocco, C., Zolla, V., Napolitano, F., \& Zolla, L. (2012). Love me tender: An omics window on the bovine meat tenderness network. Journal of Proteomics, 75(14), 4360-4380.

Daudin, J. D., Sharedeh, D., Favier, R., Portanguen, S., Auberger, J. M., \& Kondjoyan, A. (2016). Design of a new laboratory tumbling simulator for chunked meat: Analysis, reproduction and measurement of mechanical treatment. Journal of Food Engineering, 170, 83-91.
Deng, S. Y., Wang, D. Y., Zhang, M. H., Geng, Z. M., Sun, C., Bian, H., et al. (2016). Application and optimization of the tenderization of pig Longissimus dorsi muscle by adenosine 5'-monophosphate (AMP) using the response surface methodology. Animal Science Journal, 87(3), 439-448.

Desagher, S., \& Martinou, J. C. (2000). Mitochondria as the central control point of apoptosis. Trends in Cell Biology, 10(9), 369-377.

Devlin, D. J., Gault, N. F. S., Moss, B. W., Tolland, E., Tollerton, J., Farmer, L. J., et al. (2017). Factors affecting eating quality of beef. Advances in Animal Biosciences, 8(1), s2-s5.

Dominguez-Hernandez, E., Salaseviciene, A., \& Ertbjerg, P. (2018). Lowtemperature long-time cooking of meat: Eating quality and underlying mechanisms. Meat Science, 143, 104-113.

Ergezer, H., \& Gokce, R. (2011). Comparison of marinating with two different types of marinade on some quality and sensory characteristics of Turkey breast meat. Journal of Animal and Veterinary Advances, 10(1), 60-67.

Ertbjerg, P., Christiansen, L. S., Pedersen, A. B., \& Kristensen, L. (2012). The effect of temperature and time on activity of calpain and lysosomal enzymes and degradationof desmin in porcine longissimus muscle. In Paper presented at the 58th International Congress of Meat Science \& Technology, Montreal, Canada, August 12. https://doi.org/10.1088/1742-6596/445/1/012003.

Ertbjerg, P., Mielche, M. M., Larsen, L. M., \& Møller, A. J. (1999). Relationship between proteolytic changes and tenderness in prerigor lactic acid marinated beef. Journal of the Science of Food and Agriculture, 79(7), 970-978.

Ertbjerg, P., \& Puolanne, E. (2017). Muscle structure, sarcomere length and influences on meat quality: A review. Meat Science, 132, 139-152.

Etherington, D. J. (1976). Bovine spleen cathepsin B1 and collagenolytic cathepsin. A comparative study of the properties of the two enzymes in the degradation of native collagen. The Biochemical Journal, 153(2), 199-209.

Faridnia, F., Bekhit, A. E.-D. A., Niven, B., \& Oey, I. (2014). Impact of pulsed electric fields and post-mortem vacuum ageing on beef longissimus thoracis muscles. International Journal of Food Science and Technology, 49(11), 2339-2347.

Faridnia, F., Bremer, P., Burritt, D. J., \& Oey, I. (2016). Effects of pulsed electric fields on selected quality attributes of beef outside flat (Biceps femoris). In T. Jarm, \& P. Kramar (Eds.), $1^{\text {st }}$ world congress on electroporation and pulsed electric fields in biology, Medicine and Food and Environmental Technologies (WC 2015), IFMBE Proceedings, (vol. 51, 53rd ed., ). https://doi.org/10.1007/978981-287-817-5_12.

Foegeding, E. A., \& Larick, D. K. (1986). Tenderization of beef with bacterial collagenase. Meat Science, 18, 201-214.

Fu, Y., Bak, K. H., Liu, J., De Gobba, C., Tostesen, M., Hansen, E. T., et al. (2019). Protein hydrolysates of porcine hemoglobin and blood: Peptide characteristics in relation to taste attributes and formation of volatile compounds. Food Research International, 121, 28-38.

Fu, Y., Liu, J., Zhang, W., Waehrens, S. S., Tostesen, M., Hansen, E. T., et al. (2020). Exopeptidase treatment combined with Maillard reaction modification of protein hydrolysates derived from porcine muscle and plasma: Structuretaste relationship. Food Chemistry, 306, 125613.

Gagaoua, M., Bonnet, M., Ellies, M. P., De Koning, L., \& Picard, B. (2018). Reverse phase protein arrays for the identification/validation of biomarkers of beef texture and their use for early classification of carcasses. Food Chemistry, 250, 245-252.

Gagaoua, M., Terlouw, E. M., Boudjellal, A., \& Picard, B. (2015). Coherent correlation networks among protein biomarkers of beef tenderness: What they reveal. Journal of Proteomics, 128, 365-374.

Geesink, G. H., Bekhit, A. D., \& Bickerstaffe, R. (2000). Rigor temperature and meat quality characteristics of lamb longissimus muscle. Journal of Animal Science, 78, 2842-2848.

Giménez, B., Graiver, N., Califano, A., \& Zaritzky, N. (2015). Physicochemical characteristics and quality parameters of a beef product subjected to chemical preservatives and high hydrostatic pressure. Meat Science, 100, 179-188.

Girard, I., Bruce, H. L., Basarab, J. A., Larsen, I. L., \& Aalhus, J. L. (2012). Contribution of myofibrillar and connective tissue components to the Warner-Bratzler shear force of cooked beef. Meat Science, 92(4), 775-782.

Got, F., Culioli, J., Berge, P., Vignon, X., Astruc, T., Quideau, J. M., et al. (1999). Effects of high-intensity high-frequency ultrasound on ageing rate, ultrastructure and some physico-chemical properties of beef. Meat Science, $51(1), 35-42$.

Guillemin, N., Jurie, C., Cassar-Malek, I., Hocquette, J. F., Renand, G., \& Picard, B. (2011). Variations in the abundance of 24 protein biomarkers of beef tenderness according to muscle and animal type. Animal, 5, 885-894. 
Guillou, S., Lerasle, M., Simonin, H., \& Federighi, M. (2016). High-pressure processing of meat and meat products. In J. Cummins, \& J. G. Lyng (Eds.) Emerging technologies in meat processing: production, processing, and technology, (1st ed., pp. 37-101). UK: Wiley. https://doi.org/10.1002/97811183 50676.ch3.

Guo, X. Y., Peng, Z. Q., Zhang, Y. W., Liu, B., \& Cui, Y. Q. (2015). The solubility and conformational characteristics of porcine myosin as affected by the presence of L-lysine and L-histidine. Food Chemistry, 170, 212-217.

Ha, M., Bekhit, A. E.-D. A., Carne, A., \& Hopkins, D. L. (2012). Characterisation of commercial papain, bromelain, actinidin and zingibain protease preparations and their activities toward meat proteins. Food Chemistry, 134(1), 95-105.

Harper, G. S. (1999). Trends in skeletal muscle biology and the understanding of toughness in beef. Australian Journal of Agricultural Research, 50(7), 1105-1129.

Hayakawa, T., Ito, T., Wakamatsu, J., Nishimura, T., \& Hattori, A. (2010). Myosin filament depolymerizes in a low ionic strength solution containing Lhistidine. Meat Science, 84(4), 742-746.

Hopkins, D. L., \& Thompson, J. M. (2001). The relationship between tenderness, proteolysis, muscle contraction and dissociation of actomyosin. Meat Science, $57(1), 1-12$

Hou, Q., Liu, R., Tian, X. N., \& Zhang, W. G. (2020). Involvement of protein Snitrosylation in regulating beef apoptosis during postmortem aging. Food Chemistry, 326, 126975.

Huang, F., Ding, Z. J., Zhang, C. J., Hu, H. H., Zhang, L., \& Zhang, H. (2017). Effects of calcium and zinc ions injection on caspase-3 activation and tenderness in post-mortem beef skeletal muscles. International Journal of Food Science and Technology, 53(3), 582-589.

Huang, H., Larsen, M. R., \& Lametsch, R. (2012). Changes in phosphorylation of myofibrillar proteins during postmortem development of porcine muscle. Food Chemistry, 134(4), 1999-2006.

Huang, M., Huang, F., Xue, M., Xu, X. X., \& Zhou, G. H. (2011). The effect of active caspase-3 on degradation of chicken myofibrillar proteins and structure of myofibrils. Food Chemistry, 128, 22-27.

Huff-Lonergan, E., Mitsuhashi, T., Beekman, D. D., Parrish, F. C., Olson, D. G., \& Robson, R. M. (1996). Proteolysis of specific muscle structural proteins by mucalpain at low $\mathrm{pH}$ and temperature is similar to degradation in postmortem bovine muscle. Journal Animal Science, 74, 993-1008.

Huff-Lonergan, E., Zhang, W. G., \& Lonergan, S. M. (2010). Biochemistry of postmortem muscle - lessons on mechanisms of meat tenderization. Meat Science, 86, 184-195.

Hughes, J. M., Oiseth, S. K., Purslow, P. P., \& Warner, R. D. (2014). A structural approach to understanding the interactions between colour, water-holding capacity and tenderness. Meat Science, 98(3), 520-532.

Hwang, Y. H., Sabikun, N., Ismail, I., \& Joo, S. T. (2018). Comparison of meat quality characteristics of wet- and dry-aging pork belly and shoulder blade. Korean Journal for Food Science of Animal Resources, 38(5), 950-958.

Ilian, M. A., Bickerstaffe, R., \& Greaser, M. L. (2004). Postmortem changes in myofibrillar-bound calpain 3 revealed by immunofluorescence microscopy. Meat Science, 66, 231-240

Inguglia, E. S., Zhang, Z. H., Tiwari, B. K., Kerry, J. P., \& Burgess, C. M. (2017). Salt reduction strategies in processed meat products - A review. Trends in Food Science and Technology, 59, 70-78.

Jacob, R. H., \& Hopkins, D. L. (2014). Techniques to reduce the temperature of beef muscle early in the post mortem period - a review. Animal Production Science, 54, 482-493.

Jayasooriya, S. D., Torley, P. J., D'Arcy, B. R., \& Bhandari, B. R. (2007). Effect of high power ultrasound and ageing on the physical properties of bovine Semitendinosus and Longissimus muscles. Meat Science, 75(4), 628-639.

Jin, G. F., He, L. C., Li, C. L., Zhao, Y. H., Chen, C., Zhang, Y. H., et al. (2015). Effect of pulsed pressure-assisted brining on lipid oxidation and volatiles development in pork bacon during salting and drying-ripening. LWT - Food Science and Technology, 64(2), 1099-1106.

Kang, D. C., Zou, Y. H., Cheng, Y. P., Xing, L. J., Zhou, G. H., \& Zhang, W. G. (2016). Effects of power ultrasound on oxidation and structure of beef proteins during curing processing. Ultrasonics Sonochemistry, 33, 47-53.

Kantono, K., Hamid, N., Oey, I., Wang, S., Xu, Y., Ma, Q. L., et al. (2019). Physicochemical and sensory properties of beef muscles after pulsed electric field processing. Food Research International, 121, 1-11.

Ke, S., Huang, Y., Decker, E. A., \& Hultin, H. O. (2009). Impact of citric acid on the tenderness, microstructure and oxidative stability of beef muscle. Meat Science, 82(1), 113-118.
Kemp, C. M., \& Parr, T. (2012). Advances in apoptotic mediated proteolysis in meat tenderisation. Meat Science, 92(3), 252-259.

Kim, H. J., \& Taub, I. A. (1991). Specific degradation of myosin in meat by bromelain. Food Chemistry, 40, 337-343.

Kim, N. K., Cho, S., Lee, S. H., Park, H. R., Lee, C. S., Cho, Y. M., et al. (2008). Proteins in longissimus muscle of Korean native cattle and their relationship to meat quality. Meat Science, 80(4), 1068-1073.

Kim, Y. H. B., Warner, R. D., \& Rosenvold, K. (2014). Influence of high pre-rigor temperature and fast $\mathrm{pH}$ fall on muscle proteins and meat quality: A review. Animal Production Science, 54(4), 375-395.

Kloss, L., Meyer, J. D., Graeve, L., \& Vetter, W. (2015). Sodium intake and its reduction by food reformulation in the European Union - A review. NFS Journal, 1, 9-19.

Koohmaraie, M. (1992). The role of $\mathrm{Ca}^{2+}$-dependent proteases (calpains) in postmortem proteolysis and meat tenderness. Biochimie, 74, 239-245.

Koohmaraie, M., \& Geesink, G. H. (2006). Contribution of postmortem muscle biochemistry to the delivery of consistent meat quality with particular focus on the calpain system. Meat Science, 74(1), 34-43.

Lafarga, T., \& Hayes, M. (2014). Bioactive peptides from meat muscle and byproducts: Generation, functionality and application as functional ingredients. Meat Science, 98(2), 227-239.

Lametsch, R., \& Bendixen, E. (2001). Proteome analysis applied to meat science: characterizing postmortem changes in porcine muscle. Journal of Agricultural and Food Chemistry, 49(10), 4531-4537.

Lee, J. Y., Lori, D., Wells, D. J., \& Kemp, P. R. (2015). FHL1 activates myostatin signalling in skeletal muscle and promotes atrophy. FEBS Open Bio, 5, 753762.

LeMaster, M. N., Chauhan, S. S., Wick, M. P., Clark, D. L., \& England, E. M. (2019). Potassium carbonate improves fresh pork quality characteristics. Meat Science, 156, 222-230.

Li, K., Kang, Z. L., Zhao, Y. Y., Xu, X. L., \& Zhou, G. H. (2014). Use of high-intensity ultrasound to improve functional properties of batter suspensions prepared from PSE-like chicken breast meat. Food and Bioprocess Technology, 7(12), 3466-3477.

Li, S., Xu, X., \& Zhou, G. (2012). The roles of the actin-myosin interaction and proteolysis in tenderization during the aging of chicken muscle. Poultry Science, 91(1), 150-160.

Li, S. J., Ma, R. C., Pan, J. F., Lin, X. P., Dong, X. P., \& Yu, C. X. (2019). Combined effects of aging and low temperature, long time heating on pork toughness. Meat Science, 150, 33-39.

Li, S. Y., Li, L. X., Zhu, X. X., Ning, C., Cai, K. Z., \& Zhou, C. L. (2019). Conformational and charge changes induced by ${ }_{L}$-Arginine and ${ }_{L}$-lysine increase the solubility of chicken myosin. Food Hydrocolloids, 89, 330-336.

Li, X., Sun, Y. Y., Pan, D. D., Wang, Y., \& Cao, J. X. (2017). The effect of $\mathrm{CaCl}_{2}$ marination on the tenderizing pathway of goose meat during conditioning. Food Research International, 102, 487-492.

Li, Y., Liu, R., Zhang, W. G., Fu, Q. Q., Liu, N., \& Zhou, G. H. (2014). Effect of nitric oxide on $\mu$-calpain activation, protein proteolysis, and protein oxidation of pork during post-mortem aging. Journal of Agricultural and Food Chemistry, 62(25), 5972-5977.

Liu, R., Li, Y. P., Wang, M. Q., Zhou, G. H., \& Zhang, W. G. (2016). Effect of protein S-nitrosylation on autolysis and catalytic ability of $\mu$-calpain. Food Chemistry, $213,470-477$.

Liu, Z. W., Gao, T. H., Yang, Y., Meng, F. X., Zhan, F. P., Jiang, Q. C., et al. (2019). Anti-cancer activity of porphyran and carrageenan from red seaweeds. Molecules, 24(23), 4286.

Locker, R. H., \& Hagyard, C. J. (1963). A cold shortening effect in beef muscle. Journal of the Science of Food and Agriculture, 14, 787-793.

Lomiwes, D., Farouk, M. M., Wiklund, E., \& Young, O. A. (2014a). Small heat shock proteins and their role in meat tenderness: A review. Meat Science, 96(1), 2640.

Lomiwes, D., Hurst, S. M., Dobbie, P., Frost, D. A., Hurst, R. D., Young, O. A., et al. (2014b). The protection of bovine skeletal myofibrils from proteolytic damage post mortem by small heat shock proteins. Meat Science, 97, 548557.

Lyng, J. G., Allen, P., \& Mckenna, B. M. (2007). The influence of high intensity ultrasound baths on aspects of beef tenderness. Journal of Muscle Foods, 8(3) 237-249.

Ma, D. Y., \& Kim, Y. H. B. (2020). Proteolytic changes of myofibrillar and small heat shock proteins in different bovine muscles during aging: Their relevance to tenderness and water-holding capacity. Meat Science, 163, 108090. 
Malheiros, J. M., Braga, C. P., Grove, R. A., Ribeiro, F. A., Calkins, C. R., Adamec, J., et al. (2019). Influence of oxidative damage to proteins on meat tenderness using a proteomics approach. Meat Science, 148, 64-71.

Mandic, A., Viktorsson, K., Strandberg, L., Heiden, T., Hansson, J., Linder, S., \& Shoshan, M. C. (2002). Calpain-mediated bid cleavage and calpainindependent Bak modulation: Two separate pathways in cisplatin-induced apoptosis. Molecular and Cellular Biology, 22(9), 3003-3013.

Maqsood, S., Manheem, K., Gani, A., \& Abushelaibi, A. (2018). Degradation of myofibrillar, sarcoplasmic and connective tissue proteins by plant proteolytic enzymes and their impact on camel meat tenderness. Journal of Food Science and Technology, 55(9), 3427-3438.

McArdle, R. A., Marcos, B., Kerry, J. P., \& Mullen, A. M. (2011). Influence of HPP conditions on selected beef quality attributes and their stability during chilled storage. Meat Science, 87(3), 274-281.

McArdle, R. A., Marcos, B., Mullen, A. M., \& Kerry, J. P. (2013). Influence of HPP conditions on selected lamb quality attributes and their stability during chilled storage. Innovative Food Science and Emerging Technologies, 19, 66-72.

McDonnell, C. K., Allen, P., Chardonnereau, F. S., Arimi, J. M., \& Lyng, J. G. (2014). The use of pulsed electric fields for accelerating the salting of pork. LWT Food Science and Technology, 59, 1054-1060.

Melody, J. L., Lonergan, S. M., Rowe, L. J., Huiatt, T. W., Mayes, M. S., \& HuffLonergan, E. (2004). Early postmortem biochemical factors influence tenderness and water holding capacity of three porcine muscles. Journal of Animal Science, 82, 1195-1205.

Miller, M. F., Carr, M. F., Ramsey, C. B., Crockett, K. L., \& Hoover, L. C. (2001). Consumer thresholds for establishing the value of beef tenderness. Journal of Animal Science, 79, 3062-3068.

Montowska, M., \& Pospiech, E. (2013). Species-specific expression of various proteins in meat tissue: Proteomic analysis of raw and cooked meat and meat products made from beef, pork and selected poultry species. Food Chemistry, 136, 1461-1469.

Nishimura, T. (2015). Role of extracellular matrix in development of skeletal muscle and postmortem aging of meat. Meat Science, 109, 48-55.

Nishimura, T., Hattori, A., \& Takahashi, K. (1996). Relationship between degradation of proteoglycans and weakening of the intramuscular connective tissue during post-mortem ageing of beef. Meat Science, 42(3), 251-260.

O'Dowd, L. P., Arimi, J. M., Noci, F., Cronin, D. A., \& Lyng, J. G. (2013). An assessment of the effect of pulsed electrical fields on tenderness and selected quality attributes of post rigour beef muscle. Meat Science, 93(2), 303-309.

Okitani, K., Ichinose, N., Koza, M., Yamanaka, K., Migita, K., \& Matsuishi, M. (2008). AMP and IMP dissociate actomyosin into actin and myosin. Bioscience Biotechnology and Biochemistry, 72(8), 2005-2011.

Ouali, A., Gagaoua, M., Boudida, Y., Becila, S., Boudjellal, A., Herrera-Mendez, C. H., et al. (2013). Biomarkers of meat tenderness: Present knowledge and perspectives in regards to our current understanding of the mechanisms involved. Meat Science, 95(4), 854-870.

Pen, S., Kim, Y. H., Luc, G., \& Young, O. A. (2012). Effect of pre rigor stretching on beef tenderness development. Meat Science, 92(4), 681-686.

Phillips, A. L., Means, W. J., Kalchayanand, N., McCormick, R. J., \& Miller, K. W. (2000). Bovine placental protease specificity toward muscle connective tissue proteins. American Society of Animal Science, 78, 1861-1866.

Piatkov, K. I., Oh, J. H., Liu, Y., \& Varshavsky, A. (2014). Calpain-generated natural protein fragments as short-lived substrates of the $\mathrm{N}$-end rule pathway. Proceedings of the National Academy of Sciences of the United States of America, 111(9), 817-826.

Picard, B., Gagaoua, M., Micol, D., Cassar-Malek, l., Hocquette, J. F., \& Terlouw, C. E. (2014). Inverse relationships between biomarkers and beef tenderness according to contractile and metabolic properties of the muscle. Journal of Agricultural and Food Chemistry, 62, 9808-9818.

Pietrasik, Z., Aalhus, J. L., Gibson, L. L., \& Shand, P. J. (2010). Influence of blade tenderization, moisture enhancement and pancreatin enzyme treatment on the processing characteristics and tenderness of beef semitendinosus muscle. Meat Science, 84(3), 512-517.

Pietrasik, Z., \& Janz, J. A. M. (2010). Utilization of pea flour, starch-rich and fiberrich fractions in low fat bologna. Food Research International, 43(2), 602-608

Pietrasik, Z., \& Shand, P. J. (2005). Effects of mechanical treatments and moisture enhancement on the processing characteristics and tenderness of beef semimembranosus roasts. Meat Science, 71(3), 498-505.

Półtorak, A., Wyrwisz, J., Moczkowska, M., Marcinkowska-Lesiak, M., Stelmasiak, A., Rafalska, U., et al. (2015). Microwave vs. convection heating of bovine Gluteus Medius muscle: Impact on selected physical properties of final product and cooking yield. International Journal of Food Science and Technology, 50(4), 958-965.

Pörn-Ares, M. I., Samali, A., \& Orrenius, S. (1998). Cleavage of the calpain inhibitor, calpastatin, during apoptosis. Cell Death and Differentiation, 5(12), 1028-1033.

Puolanne, E., \& Halonen, M. (2010). Theoretical aspects of water-holding in meat. Meat Science, 86, 151-165.

Purchas, R. W. (1990). An assessment of the role of pH differences in determining the relative tenderness of meat from bulls and steers. Meat Science, 27(2), $129-140$

Purchas, R. W., \& Aungsupakorn, R. (1993). Further investigations into the relationship between ultimate $\mathrm{pH}$ and tenderness for beef samples from bulls and steers. Meat Science, 34, 163-178.

Purslow, P. P. (1994). The structural basis of meat toughness: What role does the collagenous compartment play? In Proceedings international congress of meat science and technology, The Hague, Netherlands, (vol. 40, pp. 27-34).

Purslow, P. P. (2018). Contribution of collagen and connective tissue to cooked meat toughness; some paradigms reviewed. Meat Science, 144, 127-134.

Qian, S. Y., Li, X., Wang, H., Wei, X. L., Mehmood, W., Zhang, C. H., et al. (2020) Contribution of calpain to protein degradation, variation in myowater properties and the water-holding capacity of pork during postmortem ageing. Food Chemistry, 324, 126892.

Ray, L., Parmanik, S., \& Bera, D. (2016). Enzymes - an existing and promising tool of food processing industry. Recent Patents on Biotechnology, 10(1), 58-71.

Rhim, J. W. (2004). Physical and mechanical properties of water resistant sodium alginate films. LWT - Food Science and Technology, 37(3), 323-330.

Roldán, M., Ruiz, J., Del Pulgar, J. S., Pérez-Palacios, T., \& Antequera, T. (2015). Volatile compound profile of sous-vide cooked lamb loins at different temperature-time combinations. Meat Science, 100, 52-57.

Saleem, R., \& Ahmad, R. (2016). Effect of low frequency ultrasonication on biochemical and structural properties of chicken actomyosin. Food Chemistry, 205, 43-51.

Sánchez Del Pulgar, J., Gázquez, A., \& Ruiz-Carrascal, J. (2012). Physico-chemical, textural and structural characteristics of sous-vide cooked pork cheeks as affected by vacuum, cooking temperature, and cooking time. Meat Science, 90(3), 828-835

Sensky, P. L., Parr, T., Bardsley, R. G., \& Buttery, P. J. (1996). The relationship between plasma epinephrine concentration and the activity of the calpain enzyme system in porcine longissimus muscle. Journal of Animal Science, 74, 380-387.

Shackelford, S. D., Wheeler, T. L., Meade, M. K., Reagan, J. O., Byrnes, B. L., \& Koohmaraie, M. (2001). Consumer impressions of tender select beef. Journal of Animal Science, 79(10), 2605-2614

Shathasivam, T., Kislinger, T., \& Gramolini, A. O. (2010). Genes, proteins and complexes: The multifaceted nature of FHL family proteins in diverse tissues. Journal of Cellular and Molecular Medicine, 14, 2702-2720.

Shen, Q. W., Swartz, D. R., Wang, Z. Y., Liu, Y., Gao, Y., \& Zhang, D. Q. (2016). Different actions of salt and pyrophosphate on protein extraction from myofibrils reveal the mechanism controlling myosin dissociation. Journal of the Science of Food and Agriculture, 96(6), 2033-2039.

Shi, H. B., Zhang, X. X., Chen, X., Fang, R., Zou, Y., Wang, D. Y., et al. (2020). How ultrasound combined with potassium alginate marination tenderizes old chicken breast meat: Possible mechanisms from tissue to protein. Food Chemistry, 328, 127144.

Sierra, V., Fernandez-Suarez, V., Castro, P., Osoro, K., Vega-Naredo, I., Garcia-Macia, M., et al. (2012). Identification of biomarkers of meat tenderisation and its use for early classification of Asturian beef into fast and late tenderising meat. Journal of the Science and Food Agriculture, 92, 2727-2740.

Sikes, A. L., \& Tume, R. K. (2014). Effect of processing temperature on tenderness, colour and yield of beef steaks subjected to high-hydrostatic pressure. Meat Science, 97(2), 244-248.

Sikes, A. L., \& Warner, R. D. (2016). Application of high hydrostatic pressure for meat tenderization. In K. Knoerzer, P. Juliano, \& G. Smithers (Eds.), Innovative food processing technologies, (pp. 259-290). New York: Springer. https://doi. org/10.1016/B978-0-08-100294-0.00010-9.

Simonin, H., Duranton, F., \& de Lamballerie, M. (2012). New insights into the highpressure processing of meat and meat products. Comprehensive Reviews in Food Science and Food Safety, 11(3), 285-306.

Smith, M. A., Bush, R. D., van de Ven, R. J., \& Hopkins, D. L. (2017). The combined effects of grain supplementation and tenderstretching on alpaca (Vicugna pacos) meat quality. Meat Science, 125, 53-60.

Smulders, F. J. M., Marsh, B. B., Swartz, D. R., Russell, R. L., \& Hoenecke, M. E. (1990). Beef tenderness and sarcomere length. Meat Science, 28, 349-363. 
Song, Y. L., Liu, L., Shen, H. X., You, J., \& Luo, Y. K. (2011). Effect of sodium alginate-based edible coating containing different anti-oxidants on quality and shelf life of refrigerated bream (Megalobrama amblycephala). Food Control, 22, 608-615.

Sørheim, O., Idland, J., Halvorsen, E. C., Frøystein, T., Lea, P., \& Hildrum, K. I. (2001). Influence of beef carcass stretching and chilling rate on tenderness of $m$. longissimus dorsi. Meat Science, 57(1), 79-85.

Stamler, J. S., Lamas, S., \& Fang, F. C. (2001). Nitrosylation: The prototypic redoxbased signaling mechanism. Cell, 106, 675-683.

Stanton, C., \& Light, N. (1988). The effects of conditioning on meat collagen: Part 2-direct biochemical evidence for proteolytic damage in insoluble perimysial collagen after conditioning. Meat Science, 23, 179-199.

Stenstrom, H., Li, X., Hunt, M. C., \& Lundstrom, K. (2014). Consumer preference and effect of correct or misleading information after ageing beef longissimus muscle using vacuum, dry ageing, or a dry ageing bag. Meat Science, 96, 661-666.

Sun, Q., Chen, F. S., Geng, F., Luo, Y. K., Gong, S. Y., \& Jiang, Z. Q. (2018). A novel aspartic protease from Rhizomucor miehei expressed in Pichia pastoris and its application on meat tenderization and preparation of turtle peptides. Food Chemistry, 245, 570-577.

Suwandy, V., Carne, A., van de Ven, R., Bekhit, A. E.-D. A., \& Hopkins, D. L. (2015a). Effect of pulsed electric field on the proteolysis of cold boned beef $M$. Longissimus lumborum and M. Semimembranosus. Meat Science, 100, 222-226.

Suwandy, V., Carne, A., van de Ven, R., Bekhit, A. E.-D. A., \& Hopkins, D. L. (2015b). Effect of pulsed electric field treatment on hot-boned muscles of different potential tenderness. Meat Science, 105, 25-31.

Suwandy, V., Carne, A., van de Ven, R., Bekhit, A. E.-D. A., \& Hopkins, D. L. (2015c). Effect of repeated pulsed electric field treatment on the quality of coldboned beef loins and topsides. Food and Bioprocess Technology, 8(6), 12181228.

Takahashi, K., Nakamura, F., Hattori, A., \& Yamanoue, M. (1985). Paratropomyosin: A new myofibrillar protein that modifies the actin-myosin interaction in postrigor skeletal muscle. I. Preparation and characterization. Journal of Biochemistry, 97(4), 1043-1051.

Tanabe, R., Tatsumi, R., \& Takahashi, K. (1994). Purification and characterization of the $1,200-\mathrm{kD}$ subfragment of connectin filaments produced by $0.1 \mathrm{mM}$ calcium ions. Journal of Biochemistry, 115(2), 351-355.

Tarze, A., Deniaud, A., Le Bras, M., Maillier, E., Molle, D., Larochette, N., et al. (2007). GAPDH, a novel regulator of the pro-apoptotic mitochondrial membrane permeabilization. Oncogene, 26, 2606-2620.

Taylor, J., Toohey, E. S., van de Ven, R., \& Hopkins, D. L. (2013). SmartStretch ${ }^{\text {TM }}$ technology VI. The impact of SmartStretch ${ }^{\text {TM }}$ technology on the meat quality of hot-boned beef striploin (m. longissimus lumborum). Meat Science, 93(3), 413-419.

Taylor, J. M., \& Hopkins, D. L. (2011). Patents for stretching and shaping meats. Recent Patents on Food Nutrition Agriculture, 3, 91-101.

Taylor, R., Tassy, C., Briand, M., Robert, N., Briand, Y., \& Ouali, A. (1995). Proteolytic activity of proteasome on myofibrillar structures. Molecular Biology Reports, 21, 71-73.

Taylor, R. G., Geesink, G. H., Thompson, V. F., Koohmaraie, M., \& Goll, D. E. (1995). Is Z-disk degradation responsible for postmortem tenderization? Journal of Animal Science, 73, 1351-1367.

Thompson, J. M., Perry, D., Daly, B., Gardner, G. E., Johnston, D. J., \& Pethick, D. W. (2006). Genetic and environmental effects on the muscle structure response post-mortem. Meat Science, 74, 59-65.

Toepfl, S. (2006). Pulsed electric fields (PEF) for permeabilization of cell membranes in food- and bioprocessing: Applications, process and equipment design and cost analysis. PhD thesis, Berlin University of Technology. https://doi.org/1 0.14279/depositonce-1441.

Toepfl, S., Siemer, C., \& Heinz, V. (2014). Effect of high-intensity electric field pulses on solid foods. In D. W. Sun (Ed.), Emerging Technologies for Food Processing, (2nd ed., pp. 147-154). Pittsburgh: Academic Press. https://doi. org/10.1016/b978-0-12-411479-1.00008-5.

Toohey, E. S., van de Ven, R., Thompson, J. M., Geesink, G. H., \& Hopkins, D. L. (2012). SmartStretch technology: V. the impact of SmartStretch technology on beef topsides ( $m$. semimembranosus) meat quality traits under commercial processing conditions. Meat Science, 92(1), 24-29.

Trout, G. R., Chen, C. M., \& Dale, S. (2010). Effect of calcium carbonate and sodium alginate on the textural characteristics, color and color stability of restructured pork chops. Journal of Food Science, 55(1), 38-42.
Tsai, L. L., Yen, N. J., \& Chou, R. G. R. (2012). Changes in Muscovy duck breast muscle marinated with ginger extract. Food Chemistry, 130(2), 316-320.

Tskhovrebova, L., \& Trinick, J. (2010). Roles of titin in the structure and elasticity of the sarcomere. Journal of Biomedicine and Biotechnology, 6, 612482.

Tullio, R. D., Passalacqua, M., Averna, M., Salamino, F., Melloni, E., \& Pontremoli, S. (1999). Changes in intracellular localization of calpastatin during calpain activation. Biochemistry, 343, 467-472.

Uytterhaegen, L., Claeys, E., \& Demeyer, D. (1994). Effects of exogenous protease effectors on beef tenderness development and myofibrillar degradation and solubility. Journal of Animal Science, 72(5), 1209-1223.

Vasquez Mejia, S. M., Shaheen, A., Zhou, Z. Y., McNeill, D., \& Bohrer, B. M. (2019). The effect of specialty salts on cooking loss, texture properties, and instrumental color of beef emulsion modeling systems. Meat Science, 156, 85-92.

Veiseth, E., Shackelford, S. D., Wheeler, T. L., \& Koohmaraie, M. (2004). Factors regulating lamb longissimus tenderness are affected by age at slaughter. Meat Science, 68(4), 635-640.

Vilar, E. G., Ouyang, H., O'Sullivan, M. G., Kerry, J. P., Hamill, R. M., O'Grady, M. N., et al. (2020). Effect of salt reduction and inclusion of $1 \%$ edible seaweeds on the chemical, sensory and volatile component profile of reformulated frankfurters. Meat Science, 161, 108001.

Wang, A. R., Kang, D. C., Zhang, W. G., Zhang, C. T., Zou, Y. H., \& Zhou, G. H. (2018). Changes in calpain activity, protein degradation and microstructure of beef M. semitendinosus by the application of ultrasound. Food Chemistry, 245, 724-730.

Wang, D. H., Xu, G. Y., Wu, D. J., \& Zheng, C. L. (2011). Molecular cloning and characterization of caprine calpastatin gene. Molecular Biology Reports, 38(6), 3665-3670.

Wang, D. Y., Deng, S. Y., Zhang, M. H., Geng, Z. M., Sun, C., Bian, H., et al. (2016). Optimization of the tenderization of duck breast meat by adenosine 5'monophosphate (AMP) using response surface methodology. Journal of Poultry Science, 53(1), 93-101.

Wang, H. L., Viatchenko-Karpinski, S., Sun, J. H., Gyorke, I., Benkusky, N. A., Kohr, M. J., et al. (2010). Regulation of myocyte contraction via neuronal nitric oxide synthase: Role of ryanodine receptor S-nitrosylation. The Journal of Physiology, 588(15), 2905-2917.

Wang, J., Liu, H. M., Wang, H. L., Cui, M. X., Jin, Q., Jin, T., et al. (2016). Isolation and characterization of a protease from the Actinidia arguta fruit for improving meat tenderness. Food Science and Biotechnology, 25(4), 1059-1064.

Wang, J. Z., \& Abe, A. (2015). A hybrid analytical model of sterilization effect on marine bacteria using microbubbles interacting with shock wave. Journal of Marine Science and Technology, 21(3), 385-395.

Wang, L. L., Yu, Q. L., Han, L., Ma, X. L., Song, R. D., Zhao, S. N., et al. (2018). Study on the effect of reactive oxygen species-mediated oxidative stress on the activation of mitochondrial apoptosis and the tenderness of yak meat. Food Chemistry, 244, 394-402

Wang, Q., Zhao, X., Ren, Y. R., Fan, E. G., Chang, H. J., \& Wu, H. B. (2013). Effects of high pressure treatment and temperature on lipid oxidation and fatty acid composition of yak (Poephagus grunniens) body fat. Meat Science, 94(4), 489494

Wang, X. W., Wang, X. J., Muhoza, B., Feng, T. T., Xia, S. Q., \& Zhang, X. M. (2020). Microwave combined with conduction heating effects on the tenderness, water distribution, and microstructure of pork belly. Innovative Food Science and Emerging Technologies, 62, 102344.

Warner, R. D., Greenwood, P. L., Pethick, D. W., \& Ferguson, D. M. (2010). Genetic and environmental effects on meat quality. Meat Science, 86(1), 171-183.

Warner, R. D., \& Ha, M. (2019). Utilising high pressure processing for meat tenderisation. In Reference module in food science, (pp. 1-6). Pittsburgh: Academic Press. https://doi.org/10.1016/b978-0-08-100596-5.21348-6.

Warner, R. D., McDonnell, C. K., Bekhit, A. E.-D. A., Claus, J., Vaskoska, R., Sikes, A., et al. (2017). Systematic review of emerging and innovative technologies for meat tenderisation. Meat Science, 132, 72-89.

Weilin, K., \& Keeton, J. (2006). Textural and physicochemical properties of low-fat, precooked ground beef patties containing carrageenan and sodium alginate. Journal of Food Science, 63(4), 571-574.

Wheeler, T. L., \& Koohmaraie, M. (1994). Prerigor and postrigor changes in tenderness of ovine Longissimus muscle. Journal of Animal Science, 72, 12321238.

Wheeler, T. L., Koohmaraie, M., \& Crouse, I. D. (1991). Effects of calcium chloride injection and hot boning on the tenderness of round muscle. Journal of Animal Science, 69(12), 4871-4875. 
Wheeler, T. L., Shackelford, S. D., Johnson, L. P., Miller, M. F., Miller, R. K., \& Koohmaraie, M. (1997). A comparison of Warner-Bratzler shear force assessment within and among institutions. Journal of Animal Science, 75(9), 2423-2432.

Whipple, G., \& Koohmaraie, M. (1992). Effects of lamb age, muscle type, and 24hour activity of endogenous proteinases on postmortem proteolysis. Journal of Animal Science, 70(3), 798-804

Wu, G., Farouk, M. M., Clerens, S., \& Rosenvold, K. (2014). Effect of beef ultimate $\mathrm{pH}$ and large structural changes with aging on meat tenderness. Meat Science, 98(4), 637-645.

Wu, W., Wan, O. W., \& Chung, K. K. (2015). S-nitrosylation of XIAP at Cys 213 of BIR2 domain impairs XIAP's anti-caspase 3 activity and anti-apoptotic function. Apoptosis, 20(4), 491-499.

Xu, J. H., Cao, H. J., Bin, Z., \& Hui, Y. (2020). The mechanistic effect of bromelain and papain on tenderization in jumbo squid (Dosidicus gigas) muscle. Food Research International, 131, 108991

Yao, J., Zhou, Y., Chen, X., Ma, F., Li, P. J., \& Chen, C. G. (2018). Effect of sodium alginate with three molecular weight forms on the water holding capacity of chicken breast myosin gel. Food Chemistry, 239, 1134-1142.

Yeh, C. M., Yang, M. C., \& Tsai, Y. C. (2002). Application potency of engineered G159 mutants on P1 substrate pocket of Subtilisin $\mathrm{YaB}$ as improved meat tenderizers. Journal of Agricultural and Food Chemistry, 50(21), 6199-6204.

Yeung, C. K., \& Huang, S. C. (2017). Effects of ultrasound pretreatment and ageing processing on quality and tenderness of pork loin. Journal of Food and Nutrition Research, 5, 809-816.

Young, R. C., \& Kools, J. (2004). Microwave oven cooking process. US patent: 10,607,131, filed Jun 27, 2003, and issued December 30, 2004. http:// europepmc.org/article/PAT/CA2529933\#full-text-links.

Yu, T., Wu, M., Huang, P., \& Hu, L. (2013). Modulating apoptosis in cancer therapy with ultrasound and high-intensity nanosecond electric pulses. In R. R. Resende, \& H. Ulrich (Eds.), Trends in Stem Cell Proliferation and Cancer Research, (1st ed., pp. 573-590). Netherlands: Springer. https://doi.org/10.1 007/978-94-007-6211-4_22.

Zhang, J. Y., Ma, G. Y., Guo, Z. B., Yu, Q. L., Han, L., Han, M. S., et al. (2018). Study on the apoptosis mediated by apoptosis-inducing-factor and influencing factors of bovine muscle during postmortem aging. Food Chemistry, 266, 359-367.

Zhang, J. Y., Yu, Q. L., Han, L., Chen, C., Li, H., \& Han, G. X. (2017). Study on the apoptosis mediated by cytochrome $\mathrm{C}$ and factors that affect the activation of bovine longissimus muscle during postmortem aging. Apoptosis, 22(6), 777785.

Zhang, M. C., Niu, H. L., Chen, Q., Xia, X. F., \& Kong, B. H. (2018). Influence of ultrasound-assisted immersion freezing on the freezing rate and quality of porcine longissimus muscles. Meat Science, 136, 1-8.

Zhang, Y. W., Zhang, L., Hui, T., Guo, X. Y., \& Peng, Z. Q. (2015). Influence of partial replacement of $\mathrm{NaCl}$ by $\mathrm{KCl}$, L-histidine and L-lysine on the lipase activity and lipid oxidation in dry-cured loin process. LWT - Food Science and Technology, 64(2), 966-973

Zhang, Y. Y., Zhang, D. J., Huang, Y. J., Chen, L., Bao, P. Q., Fang, H. M., et al. (2020). L-arginine and L-lysine degrade troponin-T, and L-arginine dissociates actomyosin: Their roles in improving the tenderness of chicken breast. Food Chemistry, 318, 126516.

Zhao, D., Xu, Y. J., Gu, T. Y., Wang, H. Y., Yin, Y. T., Sheng, B. L., et al. (2020). Peptidomic investigation of the interplay between enzymatic tenderization and the digestibility of beef semimembranosus proteins. Journal of Agricultural and Food Chemistry, 68(4), 1136-1146.

Zheng, Y. D. (2017). Effects of L-lysine/L-arginine on the physicochemical properties and quality of sodium-reduced and phosphate-free pork sausage. International Journal of Nutrition and Food Sciences, 6(1), 12-18.

Zhu, C. Z., Yin, F., Tian, W., Zhu, Y. D., Zhao, L. J., \& Zhao, G. M. (2019). Application of a pressure-transform tumbling assisted curing technique for improving the tenderness of restructured pork chops. LWT - Food Science and Technology, 111, 125-132.

Zhu, X. J., Kaur, L., Staincliffe, M., \& Boland, M. (2018a). Actinidin pretreatment and sous vide cooking of beef brisket: Effects on meat microstructure, texture and in vitro protein digestibility. Meat Science, 145, 256-265.

Zhu, X. X., Ning, C., Li, S. Y., Xu, P., Zheng, Y. D., \& Zhou, C. L. (2018b). Effects of Llysine/L-arginine on the emulsion stability, textural, rheological and microstructural characteristics of chicken sausages. International Journal of Food Science and Technology, 53(1), 88-96.
Zielbauer, B. I., Franz, J., Viezens, B., \& Vilgis, T. A. (2015). Physical aspects of meat cooking: Time dependent thermal protein denaturation and water loss. Food Biophysics, 11(1), 34-42.

Zou, Y., Shi, H. B., Xu, P. P., Jiang, D., Zhang, X. X., Xu, W. M., et al. (2019). Combined effect of ultrasound and sodium bicarbonate marination on chicken breast tenderness and its molecular mechanism. Ultrasonics Sonochemistry, 59, 104735

Zou, Y., Xu, P. P., Wu, H. H., Zhang, M. H., Sun, Z. L., Sun, C., et al. (2018). Effects of different ultrasound power on physicochemical property and functional performance of chicken actomyosin. International Journal of Biological Macromolecules, 113, 640-647.

Zou, Y., Yang, H., Zhang, M. H., Zhang, X. X., Xu, W. M., \& Wang, D. Y. (2019). The influence of ultrasound and adenosine $5^{\prime}$-monophosphate marination on tenderness and structure of myofibrillar proteins of beef. Asian-Australasian Journal of Animal Sciences, 32(10), 1611-1620.

Zuckerman, H., Bowker, B. C., Eastridge, J. S., \& Solomon, M. B. (2013). Microstructure alterations in beef intramuscular connective tissue caused by hydrodynamic pressure processing. Meat Science, 95(3), 603-607.

\section{Publisher's Note}

Springer Nature remains neutral with regard to jurisdictional claims in published maps and institutional affiliations.
Ready to submit your research? Choose BMC and benefit from:

- fast, convenient online submission

- thorough peer review by experienced researchers in your field

- rapid publication on acceptance

- support for research data, including large and complex data types

- gold Open Access which fosters wider collaboration and increased citations

- maximum visibility for your research: over $100 \mathrm{M}$ website views per year

At BMC, research is always in progress.

Learn more biomedcentral.com/submissions 